\title{
Normal Coordinate Analysis of the Vibrational Frequencies of Ethylene, Propylene, cis-2-Butene, trans-2-Butene, and Isobutene ${ }^{1}$
}

\author{
By John E. Kilpatrick ${ }^{2}$ and Kenneth S. Pitzer ${ }^{3}$
}

\begin{abstract}
The secular equations for the vibrations of ethylene, propylene, cis-2-butene, trans-2butene, and isobutene have been derived and have been factored to the greatest possible extent. A potential expression has been fitted to an assignment of vibrational frequencies for ethylene and deuteroethylene. Some of the constants so determined have.been used in deriving approximate potential expressions for propylene, cis-2-butene, trans-2-butene, and isobutene. With the vibrational frequencies calculated from these potential expressions as a guide, frequency assignments have been made for propylene, cis-2-butene, trans-2butene, and isobutene.
\end{abstract}

\section{Introduction}

This investigation was undertaken to obtain a reasonably complete understanding of the forces operating around an olefinic double bond, so that reliable statistical thermodynamic calculations could be made. The various force constants obtained will, of course, be of interest in other connections.

The number of internal degrees of freedom in the molecules of propylene, cis-2-butene, trans2 -butene, and isobutene is so large that a complete vibrational assignment from spectral data alone would be unreliable. The 1-butene molecule presents an even more difficult problem because of the complete lack of symmetry and the presence of an unbalanced rotation in the molecule.

A satisfactory assignment is available, however, for ethylene [1]. ${ }^{4}$ A potential expression was

\footnotetext{
1 This investigation was performed at the National Bureau of Standards as part of the work of the American Petroleum Institute Research Project 44 on the "Collection, analysis and calculation of data on the properties of hydrocarbons."

2 Research Associate on the American Petroleum Institute Research Project 44 at the National Bureau of Standards.

3 Associate Supervisor on the American Petroleum Institute Research Project 44, Professor of Chemistry at the University of California, Berkeley, Calif.

4 Figures in brackets indicate the literature references at the end of the paper.
}

determined that would reproduce the vibrationa? frequencies of $\mathrm{C}_{2} \mathrm{H}_{4}$ and $\mathrm{C}_{2} \mathrm{D}_{4}$. These constants were used, either directly or with reasonable modifications, and with the addition of potential constants from other molecules, to calculate the vibrational frequencies of propylene and the three rigid-frame butenes (cis-, trans-, and iso).

The assignments of many, though of course not all, of the vibrational frequencies of these molecules were obvious from spectral data alone. The uncertain potential constants (involving structural relations not found in either ethylene or any of the simple paraffins) were adjusted to fit the definitely assigned frequencies. This procedure would not have been satisfactory had the problem not involved several molecules containing the same type of bonds.

\section{Derivation of the Secular Equations}

Wilson has devised a very useful system for setting up the secular equation for the vibrations of a molecule [2]. This procedure has been used in the calculations of this report.

The secular equation is derived from the inverse of the kinetic-energy matrix $(G)$ and the potentialenergy or force-constant matrix $(F)$. Wilson's 
method is particularly well adapted to the use of internal coordinates (bond stretchings and angular distortions). The physical interpretation of the potential constants corresponding to these coordinates is simple. Furthermore, potential constants determined for a given structure in one molecule are found to hold fairly well in other similar molecules.

For a given internal coordinate $R_{k}$, a vector $\mathbf{S}_{k t}$ is defined for each atom $t$ of the molecule, so that for an arbitrary displacement $\boldsymbol{p}_{t}$,

$$
R_{k}=\sum_{t=1}^{n} \mathbf{S}_{k i} \cdot \mathbf{p}_{t}
$$

The $\mathbf{S}_{k t}$ may be calculated by rules given by Wilson. As the direction of $\mathbf{S}_{k t}$ is the displacement of atom $t$, which produces the maximum change in $R_{k}$, the various $\mathbf{S}_{k t}$ can usually be written down by inspection.

The elements of $G$, the inverse kinetic-energy matrix, are given by the expression

$$
G_{k k^{\prime}}=\sum_{t=1}^{n} \mu_{t} \mathbf{S}_{k} \cdot \mathbf{S}_{k^{\prime}}
$$

where $\mu_{t}$ is the reciprocal of the mass of the atom $t$.

If the coordinates $R_{k}$ are properly chosen with respect to the symmetry of the molecule, the matrix $G$ will be factored into a series of blocks along its diagonal. The coordinates of each block will correspond to vibrations of the same symmetry type. The $F$ matrix will be factored at least as much as the $G$ matrix. The coordinates that produce this factorization are always linear combinations of the individual bond stretchings and angular distortions, and are designated by the symbol $\boldsymbol{\pi}_{k}, \quad G$ and $F$ in terms of $\boldsymbol{\Re}_{k}$ are given the symbols $\mathbf{b}$ and $\mathrm{if}$.

\section{Ethylene}

\section{The Secular Equation}

The ethylene molecule has the symmetry of the point group $V_{h}$. This group contains eight irreducible representations, or symmetry types. Application of standard group theoretical methods $[3,4]$ leads to the general conclusions as to the symmetry and activity of the 12 vibrations summarized in table 1 .

\begin{tabular}{|c|c|c|c|c|c|c|c|c|c|c|}
\hline$V_{h}$ & $E$ & $C_{2}^{z}$ & $C_{2}^{y}$ & $C_{2}^{x}$ & $I$ & $\sigma_{2}$ & $\sigma_{y}$ & $\sigma_{x}$ & $\begin{array}{l}\text { Num- } \\
\text { ber of } \\
\text { vibra- } \\
\text { tions }\end{array}$ & $\begin{array}{l}\text { Activ- } \\
\text { ity }\end{array}$ \\
\hline$A_{1 g} \ldots$ & 1 & 1 & 1 & 1 & 1 & 1 & 1 & 1 & 3 & $R(p)$ \\
\hline$B_{1 g} \ldots$ & 1 & 1 & -1 & -1 & 1 & 1 & -1 & -1 & 2 & $R(d p)$ \\
\hline$B_{2 g} \ldots$ & 1 & -1 & 1 & -1 & 1 & -1 & 1 & -1 & 1 & $R(d p)$ \\
\hline$B_{3 g} \ldots$ & 1 & -1 & -1 & 1 & 1 & -1 & -1 & 1 & 0 & $R(d p)$ \\
\hline$A_{1 u \ldots} \ldots$ & 1 & 1 & 1 & 1 & -1 & -1 & -1 & -1 & 1 & ia \\
\hline$B_{1 u \ldots}$ & 1 & 1 & -1 & -1 & -1 & -1 & 1 & 1 & 1 & $\operatorname{IR}(z)$ \\
\hline$B_{2 u \ldots}$ & 1 & -1 & 1 & -1 & -1 & 1 & -1 & 1 & 2 & $\operatorname{IR}(y)$ \\
\hline$B_{3 u \ldots} \ldots$ & 1 & -1 & -1 & 1 & -1 & 1 & 1 & -1 & 2 & $\operatorname{IR}(x)$ \\
\hline
\end{tabular}

TABLE 1.-Symmetry characteristics of ethylene

The coordinates chosen to describe the planar motions of this molecule are the increases in the lengths of the four $\mathrm{C}-\mathrm{H}$ bonds $\left(d_{1}, d_{2}, d_{3}, d_{4}\right)$, the increases of the four $\mathrm{C}=\mathrm{C}-\mathrm{H}$ angles $\left(\alpha_{1}\right.$, $\left.\alpha_{2}, \alpha_{3}, \alpha_{4}\right)$ and the two $\mathrm{H}-\mathrm{C}-\mathrm{H}$ angles $\left(\beta_{1}, \beta_{2}\right)$, and the increase in the length of the $\mathrm{C}=\mathrm{C}$ bond $(r)$. The internal coordinates are numbered as in figure 1.

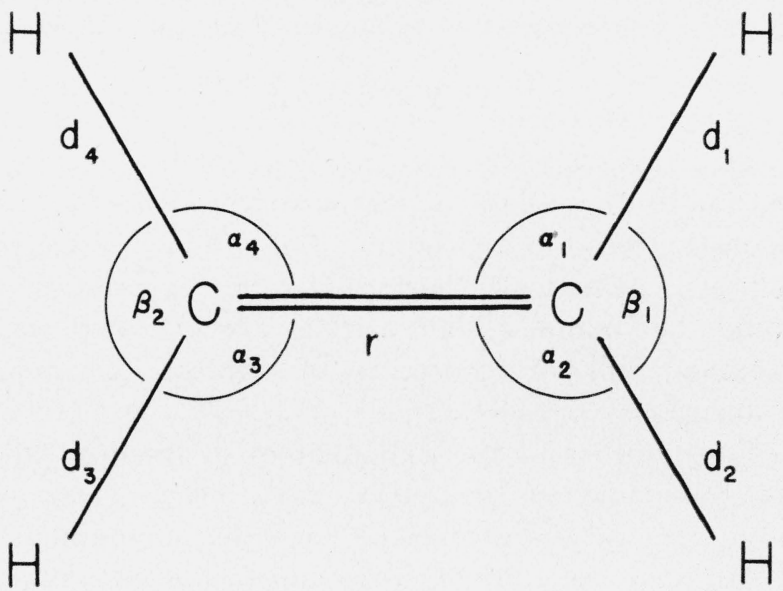

(3)

Figure 1.-Nomenclature of the coordinates used in ethylene.

In order to utilize fully the symmetry of the molecule, 11 linear combinations of the internal coordinates were formed. A fourth-order symmetry matrix was applied to the $d$ 's and one of the sixth order to the $\alpha$ 's and $\beta$ 's. Two of the angle combinations are identically zero because of the geometric relation of the angles around each carbon atom. There remain nine symmetry coordinates, which agrees with the fact that there are nine planar vibrations. The symmetry com- 
binations, each identified with its irreducible representation, are

$$
\begin{aligned}
& A_{1 g} \quad \boldsymbol{I R}_{1}=\frac{1}{2}\left(d_{1}+d_{2}+d_{3}+d_{4}\right) \\
& B_{3 u} \quad \boldsymbol{\sim}_{2}=\frac{1}{2}\left(d_{1}+d_{2}-d_{3}-d_{4}\right) \\
& B_{1 g} \quad \tilde{R}_{3}=\frac{1}{2}\left(d_{1}-d_{2}+d_{3}-d_{4}\right) \\
& B_{2 u} \quad \boldsymbol{T}_{4}=\frac{1}{2}\left(d_{1}-d_{2}-d_{3}+d_{4}\right) \\
& \boldsymbol{R}_{5}=\frac{1}{6} \sqrt{6}\left(\beta_{1}+\alpha_{1}+\alpha_{2}+\beta_{2}+\alpha_{3}+\alpha_{4}\right) \equiv 0 \\
& \tilde{\mathcal{R}}_{6}=\frac{1}{6} \sqrt{6}\left(\beta_{1}+\alpha_{1}+\alpha_{2}-\beta_{2}-\alpha_{3}-\alpha_{4}\right) \equiv 0 \\
& A_{1 g} \quad \boldsymbol{Z}_{7}=\frac{1}{6}\left(-2 \beta_{1}+\alpha_{1}+\alpha_{2}-2 \beta_{2}+\alpha_{3}+\alpha_{4}\right) \\
& =\frac{1}{2}\left(\alpha_{1}+\alpha_{2}+\alpha_{3}+\alpha_{4}\right) \\
& B_{3 u} \quad \boldsymbol{R}_{8}=\frac{1}{6}\left(-2 \beta_{1}+\alpha_{1}+\alpha_{2}+2 \beta_{2}-\alpha_{3}-\alpha_{4}\right) \\
& =\frac{1}{2}\left(\alpha_{1}+\alpha_{2}-\alpha_{3}-\alpha_{4}\right) \\
& B_{1 g} \quad \tilde{R}_{9}=\frac{1}{2}\left(\alpha_{1}-\alpha_{2}+\alpha_{3}-\alpha_{4}\right) \\
& B_{2 u} \quad \tilde{\boldsymbol{R}}_{10}=\frac{1}{2}\left(\alpha_{1}-\alpha_{2}-\alpha_{3}+\alpha_{4}\right) \\
& A_{1 g} \quad \boldsymbol{\pi}_{11}=r
\end{aligned}
$$

If the two $\beta$ 's had been ignored and the four $\alpha$ 's combined with a fourth-order symmetry matrix, the same symmetry coordinates would have been obtained. However, a large $\alpha_{1}, \alpha_{2}$ interaction term would then have been necessary in the potential expression in order to account for the $\beta$ bending energy.

The coordinates chosen to describe the out-ofplane vibrations are the angle of torsion, $\phi$, between the two $\mathrm{CH}_{2}$ groups and the two angles, $\gamma^{\prime}$ and $\gamma^{\prime \prime}$, between the $\mathrm{C}=\mathrm{C}$ bond and the bisectors of the two $\mathrm{CH}_{2}$ groups. The proper symmetry coordinates are then: $\tilde{\mathbb{R}}_{12}=\phi, A_{1 u}$; $\boldsymbol{\mathcal { R }}_{13}=\sqrt{\frac{1}{2}}\left(\gamma^{\prime}-\gamma^{\prime \prime}\right), B_{2 g}$ (chair, or trans, bending); $\boldsymbol{R}_{14}=\sqrt{\frac{1}{2}}\left(\gamma^{\prime}+\gamma^{\prime \prime}\right), B_{1 u}$ (boat, or cis, bending).

The symmetry coordinates were used to set up the inverse kinetic-energy matrices ( $(\mathbf{z})$ and the potential-energy matrices ( $\mathbf{f})$ for each symmetry type. The roots $\lambda$ of each equation

$$
\|\boldsymbol{G} \mathfrak{G} \mathbf{Y}-\lambda E\|=0
$$

yield the several vibrational frequencies by means of the equation $\lambda=4 \pi^{2} \nu^{2}$.

Such determinantal equations can readily be expanded into the usual secular equations. In matrix notation, the nature of the kinetic coupling of the several symmetry coordinates in each irreducible representation can be seen by inspection.
The elements of the $\mathbf{f}$ matrices are the coefficients of the potential-energy expression as a quadratic function of the symmetry coordinates. Furthermore, no choice of potential interaction terms need be made until the final expansion of the matrix equations to the secular equations.

Gallaway and Barker [1] found the $\mathrm{H}-\mathrm{C}-\mathrm{H}$ angle of $\mathrm{C}_{2} \mathrm{H}_{4}$ and of $\mathrm{C}_{2} \mathrm{D}_{4}$ to be $119^{\circ} 55^{\prime} \pm 30^{\prime}$. We have used the even value of $120^{\circ}$. In the following equations, $\mu_{\mathrm{H}}$ and $\mu_{\mathrm{C}}$ are the reciprocals of the masses of the hydrogen and carbon atoms. $\epsilon$ and $\tau$ are the reciprocals of the equilibrium $\mathrm{C}-\mathrm{H}$ and $\mathrm{C}=\mathrm{C}$ bond lengths, respectively.

The $\mathbf{0}$ and if matrices for the seven symmetry types of vibration in ethylene are given in table 2 Each matrix is symmetric about the main diagonal, so only the upper half is written.

TABLE 2.-Secular matrices for ethylene

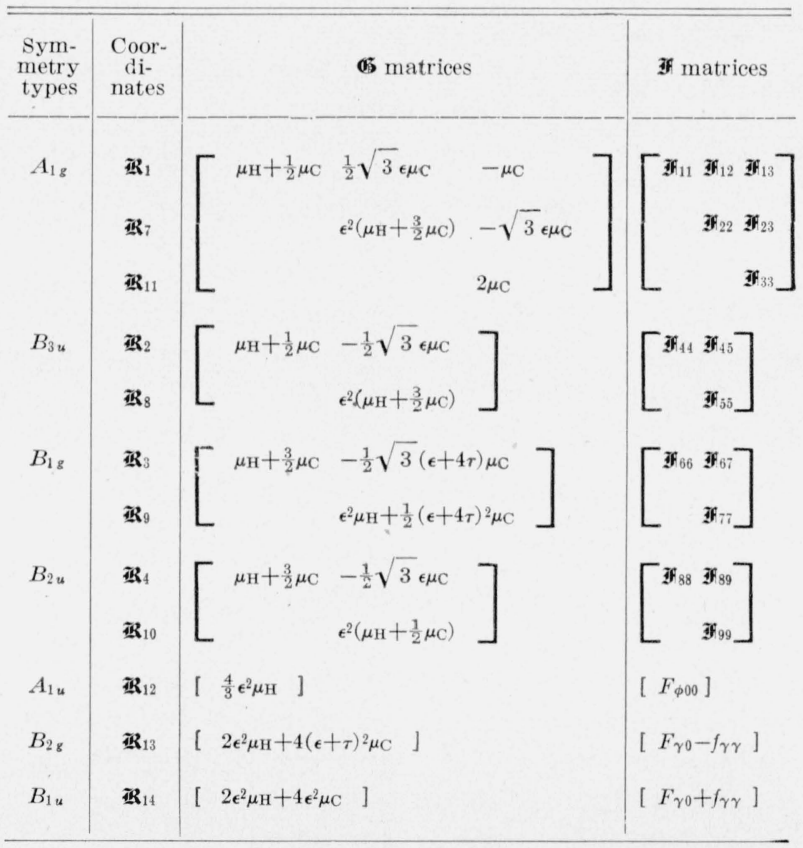

The symmetry force constants $\tilde{\mathbf{f}}_{i j}$ are related to the individual valence force constants by means of a congruent transformation with the same matrix that relates the original internal and the symmetry coordinates. As the transformation actually used - an orthonormal (symmetry) matrix with two rows altered by the factor $\sqrt{3}$-is not normalized, the following relations must be used:

$$
\begin{aligned}
& \boldsymbol{T}=U R \\
& \boldsymbol{(} \mathbf{G}=U G \tilde{U} \\
& \tilde{s}=\tilde{U} \tilde{U}^{-1} F U^{-1},
\end{aligned}
$$


where $U$ is the matrix of the transformation of eq 3 , and $\tilde{U}$ is its transpose.

The elements of ff for the planar vibrations (symmetry types $A_{1 g}, B_{3 u}, B_{1 g}, B_{2 u}$ ) are

$$
\begin{aligned}
& \mathfrak{j}_{11}=K_{\mathrm{CH}}+k_{\mathrm{CH} 12}+k_{\mathrm{CH} 13}+k_{\mathrm{CH} 14} \\
& \mathfrak{j}_{44}=K_{\mathrm{CH}}+k_{\mathrm{CH} 12}-k_{\mathrm{CH} 13}-k_{\mathrm{CH} 14} \\
& \mathfrak{i}_{66}=K_{\mathrm{CH}}-k_{\mathrm{CH} 12}+k_{\mathrm{CH} 13}-k_{\mathrm{CH} 14} \\
& \mathfrak{j}_{88}=K_{\mathrm{CH}}-k_{\mathrm{CH} 12}-k_{\mathrm{CH} 13}+k_{\mathrm{CH} 14} \\
& \mathfrak{j}_{22}=\left(H_{\alpha}+2 H_{\beta}-4 h_{\alpha \beta}\right)+h_{\alpha 12}+h_{\alpha 13}+h_{\alpha 14} \\
& \mathfrak{j}_{55}=\left(H_{\alpha}+2 H_{\beta}-4 h_{\alpha \beta}\right)+h_{\alpha 12}-h_{\alpha 13}-h_{\alpha 14} \\
& \mathfrak{j}_{77}= \\
& \mathfrak{j}_{99}= \\
& \mathfrak{j}_{33}=K_{\mathrm{CC}} \\
& \mathfrak{j}_{12}=l_{\mathrm{H} \alpha}-2 l_{\mathrm{H} \beta} \\
& \mathfrak{j}_{45}=l_{\mathrm{H} \alpha}-2 l_{\mathrm{H} \beta} \\
& \mathfrak{y}_{67}=l_{\mathrm{H} \alpha} \\
& \mathfrak{j}_{89}=l_{\mathrm{H} \alpha} \\
& \mathfrak{j}_{13}=2 k_{\mathrm{HC}} \\
& \mathfrak{i}_{23}=2\left(l_{\mathrm{C} \alpha}-l_{\mathrm{C} \beta}\right)
\end{aligned}
$$

Typical coordinates involved in each elementary force constant are

$\begin{array}{llll}K_{\mathrm{CH}} & \left(d_{i}\right)^{2} & h_{\alpha 12} & \left(\alpha_{1}\right)\left(\alpha_{2}\right) \\ K_{\mathrm{CC}} & (r)^{2} & h_{\alpha 13} & \left(\alpha_{1}\right)\left(\alpha_{3}\right) \\ H_{\alpha} & \left(\alpha_{i}\right)^{2} & h_{\alpha 14} & \left(\alpha_{1}\right)\left(\alpha_{4}\right) \\ H_{\beta} & \left(\beta_{i}\right)^{2} & h_{\alpha \beta} & \left(\alpha_{1}\right)\left(\beta_{1}\right) \\ k_{\mathrm{H} 12} & \left(d_{1}\right)\left(d_{2}\right) & l_{\mathrm{C} \alpha} & (r)\left(\alpha_{i}\right) \\ k_{\mathrm{H} 13} & \left(d_{1}\right)\left(d_{3}\right) & l_{\mathrm{C} \beta} & (r)\left(\beta_{i}\right) \\ k_{\mathrm{H} 14} & \left(d_{1}\right)\left(d_{4}\right) & l_{\mathrm{H} \alpha} & \left(d_{1}\right)\left(\alpha_{1}\right) \\ k_{\mathrm{HC}} & \left(d_{i}\right)(r) & l_{\mathrm{H} \beta} & \left(d_{1}\right)\left(\beta_{1}\right)\end{array}$

The most general quadratic potential for the planar vibrations of ethylene therefore contains 15 constants. All quadratic interactions between symmetry coordinates in different representations are identically zero. We have resolved the 15 constants into linear combinations of 16 elementary principal and interaction force constants. Five interactions involving $\mathrm{C}-\mathrm{H}$ stretching and angular distortion in different ends of the molecule have been neglected. They can readily be added by inspection or by means of a matrix operation should their consideration ever become necessary.

It is necessary to remember that in matrix notation two interactions, $F_{i j}$ and $F_{j i}$, are counted as distinct, though equal in magnitude. The total i.ateraction is the sum of the two constants.

If all of the interaction constants are set equal to zero the above matrix equations can readily be expanded to the set of secular equations given by Herzberg [5].

The vibrational assignment of Gallaway and Barker [1] was adopted for $\mathrm{C}_{2} \mathrm{H}_{4}$ and $\mathrm{C}_{2} \mathrm{D}_{4}$. These data are given in table 3 . The bond lengths given by the same authors have been used. They are equilibrium $\mathrm{C}=\mathrm{C}$ bond length, $1.353 \mathrm{~A}$, and equilibrium $\mathrm{C}-\mathrm{H}$ bond length, $1.071 \mathrm{~A}$.

TABLE 3.-Observed fundamental frequencies and their symmetry types

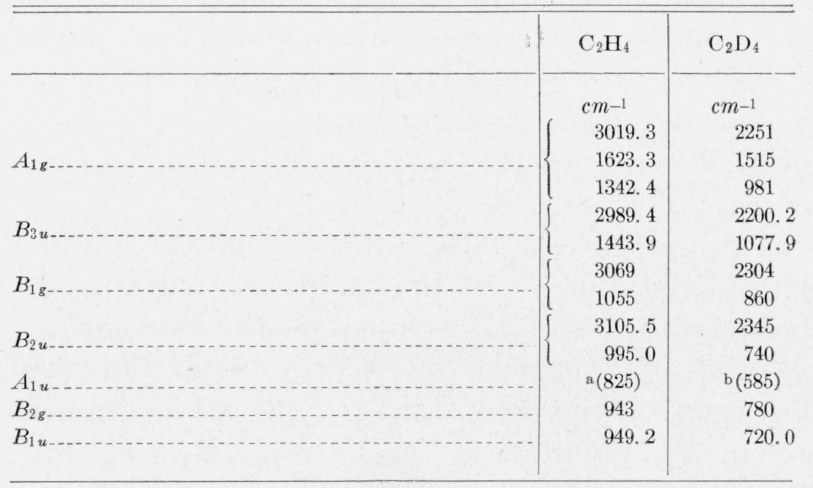

a Calculated from its second harmonic, $1654 \mathrm{~cm}-1$

b Calculated from the corresponding $\mathrm{C}_{2} \mathrm{H}_{4}$ frequency by means of the product rule.

A choice of potential constants for the totally symmetric vibrations (type $A_{1 g}$ ) presents the most difficult problem. It is not possible to find real and positive values for $\mathfrak{H}_{11}, \mathfrak{i}_{22}$, and $\mathfrak{H}_{33}$ (with the off-diagonal elements of if set equal to zero), which will yield either the three frequencies of $\mathrm{C}_{2} \mathrm{H}_{4}$ or of $\mathrm{C}_{2} \mathrm{D}_{4}$. On the basis of experience and a few trial calculations, it was decided to set $\tilde{y}_{12}$ and $\tilde{i}_{13}$ equal to zero and to find values of $\mathfrak{r}_{11}$, $\mathfrak{y}_{22}, \mathfrak{y}_{33}$, and $\mathfrak{f}_{23}$ that would most accurately yield the six observed $A_{1 g}$ frequencies of $\mathrm{C}_{2} \mathrm{H}_{4}$ and $\mathrm{C}_{2} \mathrm{D}_{4}$.

No exact solution is possible even with the most 
general potential expression with six constants. The observed $A_{1 \mathrm{~g}}$ frequencies of the two molecules fail to satisfy the product rule exactly.

Values of the above four constants that yielded the three $A_{1 g} \mathrm{C}_{2} \mathrm{H}_{4}$ frequencies exactly and that gave the closest approach to the corresponding $\mathrm{C}_{2} \mathrm{D}_{4}$ frequencies did so with a total error of 1.5 percent.

\section{Correction for Anharmonicity}

As the values of $\tilde{f}_{22}$ and $\tilde{f}_{33}$ were quite sensitive to the value of $\tilde{i}_{23}$ assumed, it was decided to attempt to correct the equations for anharmonicity in order to make a closer approach to the true potential expression. However, the data on overtones and combination tones are far from sufficient to permit a complete treatment of anharmonicity. Consequently, the method proposed by Tchang [6] was used. The masses of the hydrogen and deuterium atoms were replaced by effective masses according to the equations.

$$
\begin{aligned}
& M_{\mathrm{H}}^{\prime}=M_{\mathrm{H}}\left(1+C M_{\mathrm{H}}^{-1 / 2}\right) \\
& M_{\mathrm{D}}^{\prime}=M_{\mathrm{D}}\left(1+C M_{\mathrm{D}}^{-1 / 2}\right) .
\end{aligned}
$$

The product-rule quotient is in every case the ratio of the determinants of the $\boldsymbol{0}$ matrices for the symmetry type in question for the two isotopic molecules. In the case of $A_{1 g}$ for $\mathrm{C}_{2} \mathrm{H}_{4}$ and $\mathrm{C}_{2} \mathrm{D}_{4}$ the equation is simply

$$
\frac{M_{\mathrm{D}}^{2}}{M_{\mathrm{H}}^{2}}=\frac{\lambda_{1} \lambda_{2} \lambda_{3}}{\lambda_{1}^{\prime} \lambda_{2}^{\prime} \lambda_{3}^{\prime \prime}}
$$

where the umprimed $\lambda$ 's are for $\mathrm{C}_{2} \mathrm{H}_{4}$ and those primed for $\mathrm{C}_{2} \mathrm{D}_{4}$.

The value of $C=+0.0578$ yields values of $M_{\mathrm{H}}^{\prime}$ and $M_{\mathrm{D}}^{\prime}$, which satisfy the product rule. With this accomplished, there is a much greater possibility of finding potential constants consistent with the six observed $\mathrm{A}_{1 \mathrm{~g}}$ frequencies of the two molecules.

This correction has some theoretical basis in that it is just the form derived from the energylevel expression for a diatomic anharmonic oscillator when only first-order anharmonicity is considered. In that case, when the potential is given by $V=1 / 2 k x^{2}+a x^{3}+b x^{4}+\ldots$. . we have

$$
\begin{gathered}
\left(\epsilon_{1}-\epsilon_{o}\right) / h=\nu=\frac{k^{1 / 2}}{2 \pi M^{1 / 2}}\left(1+\frac{3 h b}{8 \pi k^{3 / 2} M^{1 / 2}}\right) \\
C \approx-(3 h b) /\left(4 \pi k^{3 / 2}\right) .
\end{gathered}
$$

In a polyatomic molecule the significance of $C$ is obscure, but it can be interpreted as a sort of composite anharmonicity coefficient.

With the hydrogen and deuterium masses corrected in this manner for anharmonicity, the force constants should be of the zeroth order, but the equations should yield the observed frequencies.

\section{Working Units for $G$ and $F$ Matrices}

Before the final results are presented, a convenient numerical transformation will be discussed. The secular equations are much easier to handle when all the elements are of the order of magnitude of unity. To achieve this end, all masses are expressed in atomic-weight units and bond lengths in angstrom units. Force constants (in cgs units) are multiplied by the factors in table 4 .

TABLE 4.-Conversion factors for force constants, cgs units to atomic-weight units

\begin{tabular}{l|r}
\hline \multicolumn{1}{|c|}{ Type of force constant } & Factor a \\
\hline & \\
\hline Principal stretching & $10^{-5} Z$ \\
Principal bending & $10^{+11} Z$ \\
Stretching-stretching interaction & $10^{-5} Z$ \\
Stretching-bending interaction & $10^{+3} Z$ \\
Bending-bending interaction & $10^{+11} Z$ \\
\hline
\end{tabular}

a Explanation of symbols:

$$
\begin{aligned}
Z & =1.69765=\frac{N_{0} 10^{5}}{4 \pi^{2} c^{2} 10^{6}} . \\
N_{0} & =\text { A vogadro's number. } \\
c & =\text { velocity of light. }
\end{aligned}
$$

The roots $\lambda$ of the secular equation are then related to the frequencies of vibration, in wave numbers, centimeters ${ }^{-1}$, through the equation

$$
\tilde{\nu}=1000 \lambda^{1 / 2} .
$$

The elements of $\mathbf{f}$ in cgs units will be designated by $\mathfrak{i f}_{i j}$ and in the above-mentioned units by, $\mathfrak{j}_{i j}^{\prime}$.

\section{Potential Constants for Ethylene}

A preliminary calculation determined that $\epsilon \mathfrak{Y}_{23}^{\prime} \cong 1.0$. A series of values in this neighborhood were chosen for $\mathfrak{j}_{23}^{\prime}$, and then by means of successive approximations the unique values of $\mathfrak{i f}_{11}^{\prime}$, $\epsilon^{2} \tilde{f}_{22}^{\prime}$, and $\mathfrak{f f}_{33}^{\prime}$ that would yield the three $A_{1 g}$ frequencies of $\mathrm{C}_{2} \mathrm{H}_{4}$ were found. The three corresponding $\mathrm{C}_{2} \mathrm{D}_{4}$ frequencies were then calculated and compared with the observed values. The error in each of the three calculated frequencies was 
plotted against ${ }_{23}^{\prime}$. The three curves intersected very nearly at a single point, which lies very nearly on the zero error axis. The data are presented in table 5 .

TABLE 5.-Calculation of force constants for the symmetry type $A_{1 g}$ of ethylene

\begin{tabular}{|c|c|c|c|c|c|c|}
\hline \multirow{2}{*}{$\epsilon \mathfrak{F}_{23}^{\prime}$} & \multirow{2}{*}{$\mathfrak{F F}_{11}^{\prime}$} & \multirow{2}{*}{$\epsilon^{2} \boldsymbol{F}_{22}^{\prime}$} & \multirow{2}{*}{$\mathbf{F F}_{33}^{\prime}$} & \multicolumn{3}{|c|}{ Calculated $\lambda^{\prime}$ s of $\mathrm{C}_{2} \mathrm{D}_{4}$} \\
\hline & & & & $\lambda_{1}$ & $\lambda_{2}$ & $\lambda_{3}$ \\
\hline (a) $1.10 \ldots \ldots$ & 9. 139 & 2. 0032 & 16. 74 & 5. 07234 & 2. 31406 & 0.95350 \\
\hline (b) $1.05 \ldots$ & 9. 141 & 2. 0254 & 16. 50 & 5. 06778 & 2. 30076 & .95988 \\
\hline (c) $1.00 \ldots \ldots$ & 9. 143 & 2. 0523 & 16. 23 & 5. 06223 & 2. 28485 & .96760 \\
\hline (d) $0.90 \ldots \ldots$ & 9.151 & 2. 1558 & 15. 35 & 5. 04149 & 2. 22065 & .99970 \\
\hline (e) $0.80^{\mathrm{a}} \ldots$ & . . . & & & - n & - n & (n) \\
\hline (f) $1.031 \ldots$ & 9.142 & 2. 0351 & 16.40 & 5. 06586 & 2. 29488 & .96270 \\
\hline \multirow{3}{*}{\multicolumn{4}{|c|}{$\begin{array}{l}\text { Observed } \lambda \text { 's of } \mathrm{C}_{2} \mathrm{D}_{4} \\
\text { Calculated } \tilde{v} \text { of } \mathrm{C}_{2} \mathrm{D}_{4} \\
\text { Observed } \tilde{v} \text { of } \mathrm{C}_{2} \mathrm{D}_{4}\end{array}$}} & 5. 06700 & 2. 29523 & .96236 \\
\hline & & & & 2250.7 & 1514.9 & 981.2 \\
\hline & & & & 2251 & 1515 & 981 \\
\hline
\end{tabular}

s No solution.

If the validity of the anharmonicity correction is granted, the essentially perfect agreement of the six calculated and six observed frequencies justifies the use of only four symmetry potential constants.

For the symmetry types $B_{3 u}, B_{1 g}$, and $B_{2 u}$ the off-diagonal symmetry potential constants were neglected as they are of the type found negligible in $A_{1 g}$. In these cases it was possible to solve directly for the two constants in each case that would yield the $\mathrm{C}_{2} \mathrm{H}_{4}$ frequencies exactly. The corresponding $\mathrm{C}_{2} \mathrm{D}_{4}$ frequencies were then calculated. The agreement with the observed $\mathrm{C}_{2} \mathrm{D}_{4}$ frequencies is fair. When the anharmonicity correction from $A_{1 g}$ is included the agreement is not essentially changed.

The lack of perfect agreement may be due to several causes. The assignments of these 12 frequencies is not as certain as is the case in $A_{1 \mathrm{~g}}$. The off-diagonal potential constants may be too important to neglect. The anharmonicity correction probably has a different value in each case, although it certainly has the same sign as in $A_{1 g}$. In all three symmetry types the agreement with the product rule was improved by the inclusion of the anharmonicity correction with the value of $\mathrm{C}$ found in $A_{1 g}$.

Probably a more elaborate treatment of anharmonicity is needed, involving different apparent masses for the motion of hydrogen atoms in the three different directions (parallel to the $\mathrm{CH}$ bond, perpendicular to the bond in the plane of the molecule and perpendicular to plane of the molecule). However, in order to evaluate all of these constants, good assignments for the mixed deuteroethylenes would probably be necessary. It was not thought that the problem was of sufficient interest to warrant further attention at the present time:

In table 6 are presented the elements of ; $^{\prime}$ and $F^{\prime}$ determined without correction for anharmonicity, together with a comparison of the calculated and observed frequencies of $\mathrm{C}_{2} \mathrm{D}_{4}$. As has been previously stated, these constants give the observed frequencies of $\mathrm{C}_{2} \mathrm{H}_{4}$ exactly. The same information, but with the correction for anharmonicity, is given in table 7. No attempt was made to correct the three out-ofplane vibrations for anharmonicity.

TABLE 6.-Force constants calculated from the frequencies of ethylene without consideration of anharmonicity

[Comparison of calculated with observed frequencies for deuteroethylene]

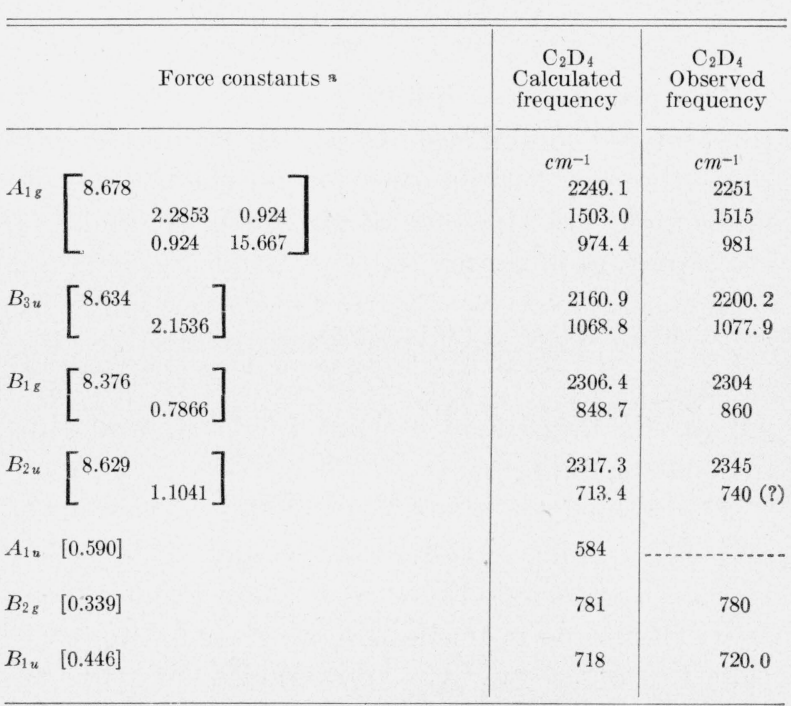

\begin{tabular}{|c|c|}
\hline $\begin{aligned} K_{\mathrm{CH}} & =8.580 \\
k_{\mathrm{H} 12} & =0.077 \\
k_{\mathrm{H} 13} & =-.053 \\
k_{\mathrm{H} 14} & =0.077 \\
K_{\mathrm{CC}} & =15.667 \\
l_{\mathrm{C} \alpha}-l_{\mathrm{C} \beta} & =0.462\end{aligned}$ & $\begin{aligned} H_{\alpha}+H_{\beta}-h_{\alpha \beta} & =1.5824 \\
H_{\alpha}-2 h_{\alpha \beta}+h_{\alpha 12} & =0.6371 \\
h_{\alpha 13} & =-.0465 \\
h_{\alpha 14} & =0.1123 \\
\text { if } h_{\alpha \beta} & =h_{\alpha 12}=0, \\
H_{\alpha} & =0.9453 \\
H_{\beta} & =0.6371\end{aligned}$ \\
\hline \multicolumn{2}{|c|}{$\begin{aligned} F_{\phi 00} & =0.590 \\
F_{\gamma 0} & =0.393 \\
F_{\gamma \gamma} & =0.054\end{aligned}$} \\
\hline
\end{tabular}

a These force constants are expressed in angstrom--atomic weight units, as previously described. 
TABLE 7.-Force constants calculated from the frequencies of ethylene with approximate correction for anharmonicity

[Comparison of calculated with observed frequencies for deuteroethylene]

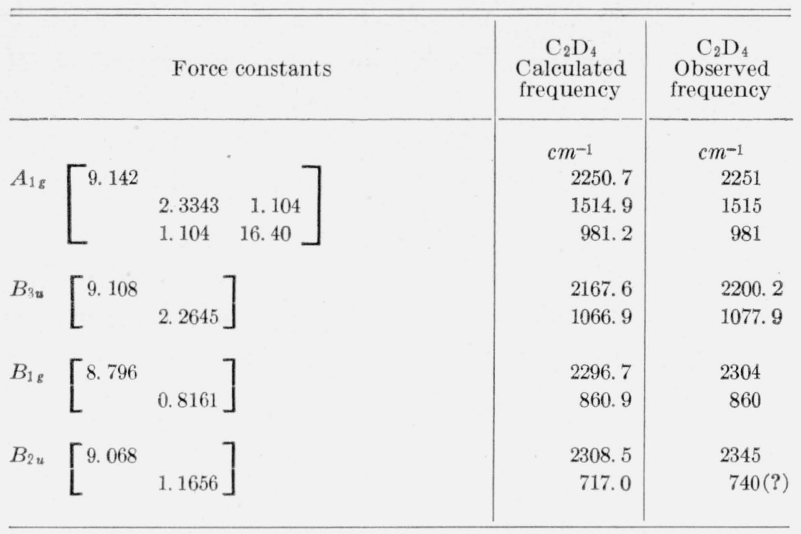

$$
\begin{array}{rr}
K_{\mathrm{CH}}=9.029 & H_{\alpha}+H_{\beta}-h_{\alpha \beta}=1.6451 \\
k_{\mathrm{H} 12}=0.097 & H_{\alpha}-h_{\alpha \beta}+h_{\alpha 12}=0.6543 \\
k_{\mathrm{H} 13}=-.079 & h_{\alpha 13}=-.0699 \\
k_{\mathrm{H} 14}=0.077 & h_{\alpha 14}=0.1048 \\
& \text { if } h_{\alpha \beta}=h_{\alpha 12}=0 \\
K_{\mathrm{CC}}=16.40 & H_{\alpha}=0.9909 \\
H_{\beta}=0.6543 \\
l_{\mathrm{C} \alpha}-l_{\mathrm{C} \beta}=0.552 \\
\text { Anharmonicity constant: } C=0.0578 .
\end{array}
$$

Some interesting conclusions can be drawn from the values of these force constants. The 13 interactions, both for $\mathrm{C}-\mathrm{H}$ stretching and for bending, are negative but are about the same absolute magnitude as the corresponding 14 (and in the case of $\mathrm{C}-\mathrm{H}$ stretching) and 12 interactions.

\section{Propylene, cis-2-Butene, trans-2- Butene, and Isobutene}

\section{Normal Equations for cis-2-Butene, trans-2- Butene, and Isobutene}

As the first step in the formulation of the complete equations for these molecules, the equations for the skeletal models, including the pair of olefinic hydrogens, were set up. The methyl groups were considered as point masses.
The numbering of the various coordinates is similar to that used for ethylene and is presented in figure 2.

The symmetry classifications and the selection rules of the three rigid frame butenes are given in table 11. The two symmetry types that are symmetrical with respect to the plane of the carbon skeleton are $A_{1}$ and $B_{2}$ for symmetry $C_{2 v}$, and $A_{g}$ and $B_{u}$ for symmetry $C_{2 h}$. Linear combinations of elementary stretchings of bonds and expansions of angles having these symmetries were formed for use as symmetry coordinates.

The coordinates that were used are the two $\mathrm{C}-\mathrm{H}$ stretchings, the two $\mathrm{C}-\mathrm{C}$ stretchings, the two $\mathrm{C}=\mathrm{C}-\mathrm{H}$ bendings, the two $\mathrm{C}=\mathrm{C}-\mathrm{C}$ bendings, and the $\mathrm{C}=\mathrm{C}$ stretching.

The proper symmetry combinations are the symmetric and antisymmetric combinations of like pairs of coordinates, written in the numerical order of their index numbers.

It was assumed that, as in ethylene, the skeletal angles are all $120^{\circ}$. The reciprocals of the $\mathrm{C}=\mathrm{C}$, $\mathrm{C}-\mathrm{H}$, and $\mathrm{C}-\mathrm{C}$ equilibrium bond lengths have been designated by $\tau, \epsilon$ and $\delta$, respectively. The reciprocals of the masses of hydrogen, carbon of a methyl group, and carbon from the olefinic group are denoted by $\mu_{\mathrm{H}}, \mu_{\mathrm{C}}$, and $\mu_{\mathrm{C}^{\prime}}$, respectively. In the case of isobutene, the reciprocal mass of the carbon of the $\mathrm{CH}_{2}$ is denoted by $\mu_{\mathrm{C}}$ " and that of the other olefinic carbon by $\mu_{\mathrm{C}^{\prime}}$.

The vibrations unsymmetrical to the skeletal plane of the molecule are $A_{u}$ and $B_{g}$ for $C_{2 h}$ and $A_{2}$ and $B_{1}$ for $C_{2 v}$. The coordinates used to describe these motions are analogous to those used for ethylene. In the case of cis- and transbutene, symmetric and antisymmetric combinations of the two $\gamma$ bendings $\left(=\mathrm{C}_{\mathrm{H}}^{\prime}{ }_{\mathrm{H}}^{-\mathrm{CH}_{3}}\right.$ against the

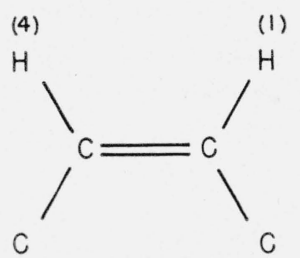

(3)

cis-2-butene

(2)

$\mathrm{C}_{2 \mathrm{v}}$

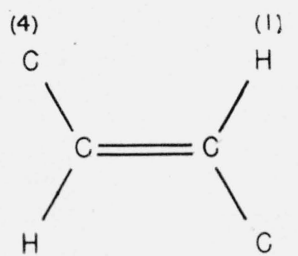

(3)

trans-2-butene

$\mathrm{C}_{2 h}$

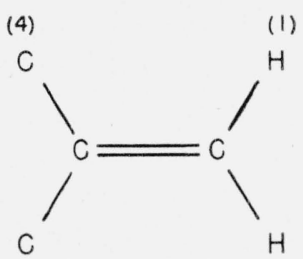

(3)

is obutene

FiguRE 2.-Numbering of the coordinates for the three butenes. 
olefinic $\mathrm{C}=\mathrm{C}$ group) were used. In isobutene the two angles were used separately .

In the early stages of this work, it was hoped that a satisfactory analysis could be completed without a detailed treatment of the methyl groups. It soon became apparent, however, that the kinetic coupling between the rocking or wagging motions of the methyl groups and the remainder of the molecule was great enough that this coordinate, at least, must be included in the normal coordinate analysis.

The 13 matrix of the skeleton of a molecule is a submatrix of the $\mathbf{0}$ matrix for the whole molecule. It is not necessary to orient the methyl groups that replace single particles so that the symmetry of the molecule is unchanged, although such might seem to be the case at first sight.

The additional elements of $\mathbf{0} \mathbf{6}$ from each methyl group are of two kinds (1) those from the eight degrees of freedom of each methyl group, and (2) those arising from the coupling of methyl and skeletal motions.

The elements of $\mathbf{0}$ arising purely from each methyl are the same as those first calculated by Wilson for $\mathrm{CH}_{3} \mathrm{X}$. The symmetry classification of the vibrations may be changed, however. For example, the doubly degenerate $(E)$ vibrations usually will separate into different symmetry classes.

Of the eight modes of vibration of a methyl group, two are parallel to the methyl axis. These are (1) symmetric $\mathrm{C}-\mathrm{H}$ stretching, (2) symmetric $\mathrm{CH}_{3}$ deformation. The six remaining modes are perpendicular to the methyl axis. These are a mutually perpendicular pair each of (3) unsymmetric $\mathrm{C}-\mathrm{H}$ stretching, (4) unsymmetric $\mathrm{CH}_{3}$ deformation, and (5) methyl wagging.

Let $\alpha_{i j}$ be the change in an $\mathrm{H}^{i} \mathrm{CH}^{j}$ angle, $\beta_{i}$ the change in an $\mathrm{XCH}^{i}$ angle, and $d_{i}$ the change in a $\mathrm{CH}^{i}$ bond. $\mathrm{X}$ is the atom to which the methyl group is attached. Eight appropriate coordinates are then:

$$
\left.\begin{array}{l}
(1 / \sqrt{3})\left(d_{1}+d_{2}+d_{3}\right) \\
(1 / \sqrt{3})\left(\alpha_{1}+\alpha_{2}+\alpha_{3}\right)
\end{array}\right\} \text { parallel to } \mathrm{CH}_{3} \text { axis. }
$$

(3)

$(1 / \sqrt{6})\left(2 d_{1}-d_{2}-d_{3}\right)$

$(1 / \sqrt{6})\left(2 \alpha_{1}-\alpha_{2}-\alpha_{3}\right)$

$(1 / \sqrt{6})\left(2 \beta_{1}-\beta_{2}-\beta_{3}\right)$

$(3)^{\prime}(1 / \sqrt{2})\left(d_{2}-d_{3}\right)$

$(4)^{\prime}(1 / \sqrt{2})\left(\alpha_{2}-\alpha_{3}\right)$

$(5)^{\prime}(1 / \sqrt{2})\left(\beta_{2}-\beta_{3}\right)$

The elements of $G$ from each methyl group are parallel vibrations:

(1)

(1) $\left[\mu_{\mathrm{H}}+\frac{1}{3} \mu_{\mathrm{C}}\right.$ perpendicular to $\mathrm{CH}_{3}$ axis.

perpendicular vibrations:

(3)

$\left.\begin{array}{l}\text { (3) } \\ \text { (4) } \\ \text { (5) }\end{array}\right]$

where $\rho$ is the reciprocal $\mathrm{C}-\mathrm{H}$ bond length and $\delta$ is the reciprocal $\mathrm{C}-\mathrm{X}$ bond length. The factor $\gamma$ is unity when only one methyl group is attached to the atom $\mathrm{X}$. When this is not the case, as in isobutene, the symmetry $\mathbf{S}$ vector for the atom $\mathrm{X}$ may have a different length than it does in the above simple case. The factor $\gamma$ is proportional to the number of methyl groups attached to atom X and to the square of the relative change in $\mathbf{S}$ from its usual value for a single methyl group.

Coupling terms between two modes of vibration can arise only through an atom, $t$, which has $\mathbf{S}_{k t}$ vectors that are nonperpendicular. Consequently, the methyl group can couple with the skeletal motions only through the methyl carbon or the atom to which the methyl group is attached. Vector $\mathbf{S}_{k t}$ for the methyl carbon is nonzero for all eight methyl motions and is parallel or perpendicular to the methyl axis, according to the type of vibration. For the atom to which the methyl group is attached, $\mathbf{S}_{k t}$ is zero except for the rocking motion of the methyl group.

The complete matrix equations for these three butenes are given in tables 8, 9, and 10 . 


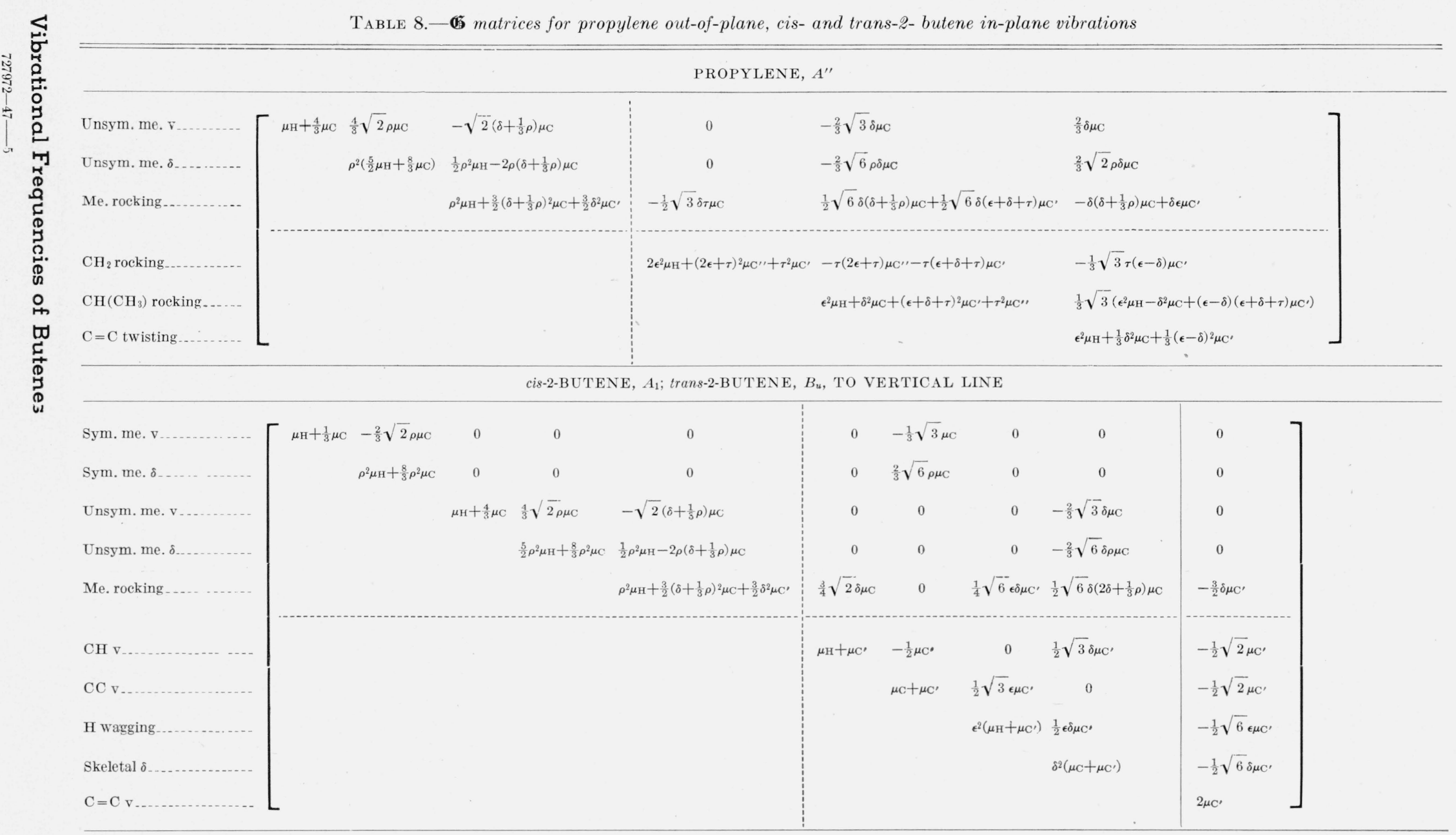


trans-2-BUTENE, $A_{\theta}$; cis-2-BUTENE, $B_{2}$, TO VERTICAL LINE

\begin{tabular}{|c|c|c|c|c|c|c|c|c|}
\hline Sym. me. v ............. & $\mu_{\mathrm{H}}+\frac{1}{3} \mu_{\mathrm{C}} \quad-\frac{2}{3} \sqrt{2} \rho \mu_{\mathrm{C}}$ & 0 & 0 & 0 & $-\frac{1}{3} \sqrt{3} \mu_{\mathrm{C}}$ & 0 & 0 & 0 \\
\hline Sym. me. $\delta \ldots \ldots$ & $\rho^{2} \mu_{\mathrm{H}}+\frac{8}{3} \rho^{2} \mu_{\mathrm{C}}$ & 0 & 0 & 0 & $\frac{2}{3} \sqrt{6} \rho \mu_{\mathrm{C}}$ & 0 & 0 & 0 \\
\hline Unsym. me. $\nabla . \ldots . .$. & & $\mu_{\mathrm{H}}+\frac{4}{3} \mu_{\mathrm{C}} \quad \frac{4}{3} \sqrt{2} \rho \mu_{\mathrm{C}}$ & $-\sqrt{2}\left(\delta+\frac{1}{3} \rho\right) \mu_{\mathrm{C}}$ & 0 & 0 & 0 & $-\frac{2}{3} \sqrt{6} \delta \mu_{\mathrm{C}}$ & 0 \\
\hline Unsym. me. $\delta \ldots$ & & $\frac{5}{2} \rho^{2} \mu_{\mathrm{H}}+\frac{8}{3} \rho^{2} \mu_{\mathrm{C}}$ & $\frac{1}{2} \rho^{2} \mu_{\mathrm{H}}-2 \rho\left(\delta+\frac{1}{3} \rho\right) \mu \mathrm{C}$ & 0 & 0 & 0 & $-\frac{2}{3} \sqrt{6} \delta \rho \mu_{\mathrm{C}}$ & 0 \\
\hline Me. rosking & & & $\rho^{2} \mu_{\mathrm{H}}+\frac{3}{2}\left(\delta+\frac{1}{3} \rho\right)^{2} \mu_{\mathrm{C}}+\frac{3}{2} \delta^{2} \mu_{\mathrm{C}^{\prime}}$ & $\frac{3}{4} \sqrt{2} \delta \mu_{\mathrm{C}^{\prime}}$ & 0 & $-\frac{1}{4} \sqrt{6} \delta(2 \tau-\epsilon) \mu_{\mathrm{C}^{\prime}}$ & $\frac{1}{2} \sqrt{6}\left(\delta\left(\delta+\frac{1}{3} \rho\right) \mu_{\mathrm{C}}+\delta(\tau+\delta) \mu_{\mathrm{C}^{\prime}}\right)$ & $-\frac{3}{2} \delta \mu_{\mathrm{C}^{\prime}}$ \\
\hline $\mathrm{CH} \mathrm{V} \ldots \ldots \ldots$ & & & & $\mu_{\mathrm{H}}+\mu_{\mathrm{C}}$ & $-\frac{1}{2} \mu_{\mathrm{C}^{\prime}}$ & $-\sqrt{3} \tau \mu_{\mathrm{C}^{\prime}}$ & $\frac{1}{2} \sqrt{3}(\delta+2 \tau) \mu_{\mathrm{C}^{\prime}}$ & $-\frac{1}{2} \sqrt{2} \mu_{\mathrm{C}^{\prime}}$ \\
\hline $\mathrm{CC}_{\mathrm{v}} \ldots \ldots$ & & & & & $\mu_{\mathrm{C}}+\mu_{\mathrm{C}^{\prime}}$ & $\frac{1}{2} \sqrt{3}(\epsilon+2 \tau) \mu_{\mathrm{C}^{\prime}}$ & $-\sqrt{3} \tau \mu_{\mathrm{C}^{\prime}}$ & $-\frac{1}{2} \sqrt{2} \mu_{\mathrm{C}^{\prime}}$ \\
\hline H wagging & & & & & & $\epsilon^{2} \mu_{\Pi}+\left(\epsilon^{2}+2 \epsilon \tau+4 \tau^{2}\right) \mu_{\mathrm{C}^{\prime}}$ & $\frac{1}{2}\left(\epsilon \delta-2 \epsilon \tau-2 \delta \tau-8 \tau^{2}\right) \mu \mathrm{C}^{\prime}$ & $-\frac{1}{2} \sqrt{6} \epsilon \mu \mathrm{C}^{\prime}$ \\
\hline Skeletal $\delta \ldots \ldots$ & & & & & & & $\delta^{2} \mu_{\mathrm{C}}+\left(\delta^{2}+2 \delta \tau+4 \tau^{2}\right) \mu_{\mathrm{C}^{\prime}}$ & $-\frac{1}{2} \sqrt{6} \delta \mu \mathrm{C}^{\prime}$ \\
\hline $\mathrm{C}=\mathrm{C} \mathrm{v}_{\ldots}$ & & & & & & & & $2 \mu_{\mathrm{C}}$ \\
\hline
\end{tabular}




\begin{tabular}{|c|c|c|c|c|c|c|c|c|c|c|c|c|}
\hline \multicolumn{13}{|c|}{ ISOBUTENE, $A_{1}$} \\
\hline Sym. me. v...... & $\mu_{\mathrm{H}}+\frac{1}{3} \mu_{\mathrm{C}}$ & $-\frac{2}{3} \sqrt{2} \rho \mu_{\mathrm{C}}$ & 0 & 0 & 0 & 0 & $-\frac{1}{3} \sqrt{3} \mu_{\mathrm{C}}$ & 0 & 0 & J & $0^{\circ}$ & \\
\hline Sym. me. $\delta \ldots \ldots$ & & $\rho^{2} \mu_{\mathrm{H}}+\frac{8}{3} \rho^{2} \mu_{\mathrm{C}}$ & 0 & 0 & 0 & 0 & $\frac{2}{3} \sqrt{6} \rho \mu_{\mathrm{C}}$ & 0 & 0 & 0 & 0 & \\
\hline Unsym. me. v...- & & & $\mu_{\mathrm{H}}+\frac{4}{3} \mu_{\mathrm{C}}$ & $\frac{4}{2} \sqrt{2} \rho \mu_{\mathrm{C}}$ & $-\sqrt{2}\left(\delta+\frac{1}{3} \rho\right) \mu_{\mathrm{C}}$ & 0 & 0 & 0 & $-\frac{2}{3} \sqrt{3} \delta \mu \mathrm{C}$ & & 0 & \\
\hline Unsym. me. $\delta . . .-$ & & & & $\frac{5}{2} \rho^{2} \mu_{\mathrm{H}}+{ }_{3}^{8} \rho^{2} \mu_{\mathrm{C}}$ & $\frac{1}{2} \rho^{z} \mu_{\mathrm{H}}-2 \rho\left(\delta+\frac{1}{3} \rho\right) \mu_{\mathrm{C}}$ & 0 & 0 & 0 & $-\frac{2}{3} \sqrt{6} \delta \rho \mu_{\mathrm{C}}$ & & 0 & \\
\hline Me. rocking -...... & & & & & $\rho^{2} \mu_{\mathrm{H}}+\frac{3}{2}\left(\delta+\frac{1}{3} \rho\right)^{2} \mu_{\mathrm{C}}+\frac{9}{4} \delta^{2} \mu_{\mathrm{C}^{\prime}}$ & 0 & $\frac{3}{4} \sqrt{2} \delta \mu_{\mathrm{C}^{\prime}}$ & 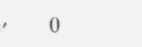 & $\frac{1}{2} \sqrt{6}\left(\delta\left(\delta+\frac{1}{3} \rho\right.\right.$ & 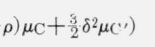 & $-\frac{3}{2} \delta \mu_{\mathrm{C}^{\prime}}$ & \\
\hline $\mathrm{C}-\mathrm{H}$ v $\ldots . . .$. & & & & & & $\mu_{\mathrm{H}}+\frac{1}{2} \mu_{\mathrm{C}^{\prime}}$ & 0 & $\frac{1}{2} \sqrt{3} \epsilon \mu_{\mathrm{C}^{\prime}}$ & 0 & 0 & $-\frac{1}{2} \sqrt{2} \mu_{\mathrm{C}^{\prime}}$ & \\
\hline $\mathrm{C}-\mathrm{C} \mathrm{v}-\ldots \ldots$ & & & & & & & $\mu_{\mathrm{C}}+\frac{1}{2} \mu_{\mathrm{C}^{\prime}}$ & 0 & $\frac{1}{2} \sqrt{3} \delta \mu_{\mathrm{C}^{\prime}}$ & & $-\frac{1}{2} \sqrt{2} \mu_{\mathrm{C}^{\prime}}$ & \\
\hline H wagging ....... & & & & & & & & $\epsilon^{2}\left(\mu_{\mathrm{H}}+\frac{3}{2} \mu_{\mathrm{C}}^{\prime \prime \prime}\right)$ & 0 & 0 & $-\frac{1}{2} \sqrt{6} \epsilon \mu_{\mathrm{C}^{\prime}}$ & \\
\hline Skeletal $\delta$ & & & & & & & & & $\delta^{2}\left(\mu \mathrm{C}+\frac{3}{2} \mu_{\mathrm{C}^{\prime}}\right)$ & & $-\frac{1}{2} \sqrt{6} \delta \mu_{\mathrm{C}^{\prime}}$ & \\
\hline $\mathrm{C}=\mathrm{C} \mathrm{v} \ldots \ldots \ldots$ & L & & & & & & & & & & $\mu_{\mathrm{C}^{\prime}}+\mu_{\mathrm{C}^{\prime \prime}}$ & \\
\hline \multicolumn{13}{|c|}{ ISOBUTENE, $B_{2}$} \\
\hline Sym. me. v...... & {$\left[\mu_{\mathrm{H}}+\frac{1}{3} \mu_{\mathrm{C}}\right.$} & $-\frac{2}{3} \sqrt{2} \rho \mu_{\mathrm{C}}$ & 0 & 0 & 0 & 0 & $-\frac{1}{3} \sqrt{3} \mu_{\mathrm{C}}$ & 0 & & 0 & & 7 \\
\hline Sym. me. $\delta \ldots \ldots$ & & $\rho^{2} \mu_{\mathrm{H}}+\frac{8}{3} \rho^{2} \mu_{\mathrm{C}}$ & 0 & 0 & 0 & 0 & $\frac{2}{3} \sqrt{6} \rho \mu_{\mathrm{C}}$ & 0 & & 0 & & \\
\hline Unsym. me. v.... & & & $\mu_{\mathrm{H}}+\frac{4}{5} \mu_{\mathrm{C}}$ & $\frac{4}{3} \sqrt{2} \rho \mu_{\mathrm{C}}$ & $-\sqrt{2}\left(\delta+\frac{1}{3} \rho\right) \mu_{\mathrm{C}}$ & 0 & 0 & 0 & & $-\frac{2}{3} \sqrt{3} \delta \mu_{\mathrm{C}}$ & & \\
\hline Unsym. me. $\delta_{-} \ldots$ & & & & $\frac{5}{2} \rho^{2} \mu_{\mathrm{H}}+\frac{8}{3} \rho^{2} \mu_{\mathrm{C}}$ & $\frac{1}{2} \rho^{2} \mu_{\mathrm{H}}-2 \rho\left(\delta+\frac{1}{3} \rho\right) \mu_{\mathrm{C}}$ & 0 & 0 & 0 & & $-\frac{2}{3} \sqrt{6} \delta \rho \mu_{\mathrm{C}}$ & & \\
\hline Me. rocking__._. & & & & & $\rho^{2} \mu_{\mathrm{H}}+\frac{3}{2}\left(\delta+\frac{1}{3} \rho\right)^{2} \mu_{\mathrm{C}}+{ }_{4}^{3} \delta^{2} \mu_{\mathrm{C}^{\prime}}$ & 0 & $-\frac{3}{4} \sqrt{2} \delta \mu_{\mathrm{C}^{\prime}}$ & $\frac{1}{2} \sqrt{6} \delta \tau \mu_{\mathrm{C}}$ & & $\frac{1}{2} \sqrt{6}\left(\delta\left(\delta+\frac{1}{3}\right)\right.$ & $\left.\left.\frac{1}{3} \rho\right) \mu_{\mathrm{C}}+\frac{1}{2} \delta(\delta+2 \tau) \mu_{\mathrm{C}^{\prime}}\right)$ & \\
\hline $\mathrm{C}-\mathrm{H} \mathrm{v}_{\ldots} \ldots$ & & & & & & $\mu_{\mathrm{H}}+\frac{3}{2} \mu_{\mathrm{C}^{\prime \prime}}$ & 0 & $-\frac{1}{2} \sqrt{3}(\epsilon+2)$ & $\mu_{\mathrm{C}^{\prime}}$ & $-\sqrt{3} \tau \mu_{\mathrm{C}^{\prime}}$ & & \\
\hline $\mathrm{C}-\mathrm{C} \mathrm{v}-\ldots . .$. & & & & & & & $\mu_{\mathrm{C}}+\frac{3}{2} \mu_{\mathrm{C}^{\prime}}$ & $-\sqrt{3} \tau \mu_{\mathrm{C}^{\prime}}$ & & $-\frac{1}{2} \sqrt{3}(\delta+2 \tau$ & $2 \tau) \mu_{\mathrm{C}^{\prime}}$ & \\
\hline H wagging . . ... . . & & & & & & & & $\epsilon^{2} \mu_{\mathrm{H}}+\frac{1}{2}(\epsilon+2$ & $\tau)^{2} \mu_{\mathrm{C}^{\prime \prime}}+2 \tau^{2} \mu_{\mathrm{C}^{\prime}}$ & $\tau(\epsilon+2 \tau) \mu_{\mathrm{C}^{\prime \prime}}+$ & $+\tau(\delta+2 \tau) \mu_{\mathrm{C}^{\prime}}$ & \\
\hline Skeletal $\delta \ldots \ldots . . .$. & $L$ & & & & & & & & & $\delta^{2} \mu_{\mathrm{C}}+\frac{1}{2}(\delta+2 \tau$ & $2)^{2} \mu_{\mathrm{C}^{\prime}}+2 \tau^{2} \mu_{\mathrm{C}^{\prime \prime}}$ & \\
\hline
\end{tabular}


ISOBUTENE, $B_{1}$

\begin{tabular}{|c|c|c|c|c|}
\hline Unsym. me. v & {$\left[\mu_{\mathrm{H}}+\frac{4}{3} \mu_{\mathrm{C}} \quad \frac{4}{3} \sqrt{2} \rho \mu_{\mathrm{C}}\right.$} & $-\sqrt{2}\left(\delta+\frac{1}{3} \rho\right) \mu_{\mathrm{C}}$ & 0 & $\frac{2}{3} \sqrt{6} \delta \mu_{\mathrm{C}}$ \\
\hline Unsym. me. $\delta \ldots$ & $\rho^{2}\left(\frac{5}{2} \mu_{\mathrm{H}}+\frac{8}{3} \mu_{\mathrm{C}}\right)$ & $\frac{1}{2} \rho^{2} \mu_{\mathrm{H}}-2 \rho\left(\delta+\frac{1}{3} \rho\right) \mu_{\mathrm{C}}$ & 0 & $\frac{4}{3} \sqrt{3} \rho \delta \mu_{\mathrm{C}}$ \\
\hline Me. rocking ...... & & $\rho^{2} \mu_{\mathrm{H}}+\frac{3}{2}\left(\delta+\frac{1}{3} \rho\right)^{2} \mu_{\mathrm{C}}+3 \delta^{2} \mu_{\mathrm{C}^{\prime}}$ & $-\sqrt{3} \delta \tau \mu_{\mathrm{C}^{\prime}}$ & $\sqrt{3} \delta\left(\delta+\frac{1}{3} \rho\right) \mu_{\mathrm{C}}+\sqrt{3} \delta(2 \delta+\tau) \mu_{\mathrm{C}^{\prime}}$ \\
\hline $\mathrm{CH}_{2}$ rocking ..... & & & $2 \epsilon^{2} \mu \mathrm{H}+(2 \epsilon+\tau)^{2} \mu_{\mathrm{C}^{\prime \prime}}+\tau^{2} \mu_{\mathrm{C}^{\prime}}$ & $-\tau(2 \epsilon+\tau) \mu_{\mathrm{C}^{\prime \prime}}-\tau(2 \delta+\tau) \mu_{\mathrm{C}^{\prime}}$ \\
\hline Skeletal $\delta \ldots \ldots \ldots$ & L & & & $2 \delta^{2} \mu_{\mathrm{C}}+(2 \delta+\tau)^{2} \mu_{\mathrm{C}^{\prime}}+\tau^{2} \mu_{\mathrm{C}^{\prime \prime}}$ \\
\hline
\end{tabular}

ISOBUTENE, $A_{2}$

\begin{tabular}{|c|c|c|c|}
\hline Unsym. me. v & {$\left[\mu_{\mathrm{H}}+\frac{4}{3} \mu_{\mathrm{C}} \quad \frac{4}{3} \sqrt{2} \rho \mu_{\mathrm{C}}\right.$} & $-\sqrt{2}\left(\delta+\frac{1}{3} \rho\right) \mu_{\mathrm{C}}$ & $\frac{2}{3} \sqrt{2} \delta \mu_{\mathrm{C}}$ \\
\hline Unsym. me. $\delta \ldots$ & $\rho^{2}\left(\frac{5}{2} \mu_{\mathrm{H}}+\frac{8}{3} \mu_{\mathrm{C}}\right.$ & $\frac{1}{2} \rho^{2} \mu_{\mathrm{H}}-2 \rho\left(\delta+\frac{1}{3} \rho\right) \mu_{\mathrm{C}}$ & ${ }_{3}^{4} \rho \delta \mu_{\mathrm{C}}$ \\
\hline Me. rocking.-.... & & $\rho^{2} \mu_{\mathrm{H}}+\frac{3}{2}\left(\delta+\frac{1}{3} \rho\right)^{2} \mu_{\mathrm{C}}$ & $-\delta\left(\delta+\frac{1}{3} \rho\right) \mu_{\mathrm{C}}$ \\
\hline $\mathrm{C}=\mathrm{C}$ twisting $\ldots$ & L & & $\frac{2}{3}\left(\epsilon^{2} \mu_{\mathrm{H}}+\delta^{2} \mu_{\mathrm{C}}\right.$ \\
\hline
\end{tabular}

\begin{tabular}{|c|c|c|c|c|}
\hline \multicolumn{5}{|c|}{ cis-2-BUTENE, $A_{2}$; trans-2-BUTENE, $B_{0}$ TO VERTICAL LINE } \\
\hline Unsym. me. $\delta$ & $\rho^{2}\left(\frac{5}{2} \mu_{\mathrm{H}}+\frac{8}{5} \mu_{\mathrm{C}}\right)$ & $\frac{1}{2} \rho^{2} \mu_{\mathrm{H}}-2 \rho\left(\delta+\frac{1}{3} \rho\right) \mu_{\mathrm{C}}$ & $-\frac{2}{3} \sqrt{6} \rho \delta \mu_{\mathrm{C}}$ & $\frac{4}{3} \rho \delta \mu_{\mathrm{C}}$ \\
\hline Me. rocking & & $\rho^{2} \mu_{\mathrm{H}}+\frac{3}{2}\left(\delta+\frac{1}{3} \rho\right)^{2} \mu_{\mathrm{C}}+\frac{3}{2} \delta^{2} \mu_{\mathrm{C}^{\prime}}$ & $\frac{1}{2} \sqrt{6} \delta\left(\delta+\frac{1}{3} \rho\right) \mu_{\mathrm{C}}+\frac{1}{2} \sqrt{6 \delta}(\epsilon+\delta+2 \tau) \mu_{\mathrm{C}^{\prime}}$ & $-\delta\left(\delta+\frac{1}{3} \rho\right) \mu_{\mathrm{C}}+\delta(\epsilon-\delta) \mu_{\mathrm{C}^{\prime}}$ \\
\hline
\end{tabular}

trans-2-BUTENE, $A_{u}$; cis-2-BUTENE, $B_{1}$, TO VERTICAL LINE

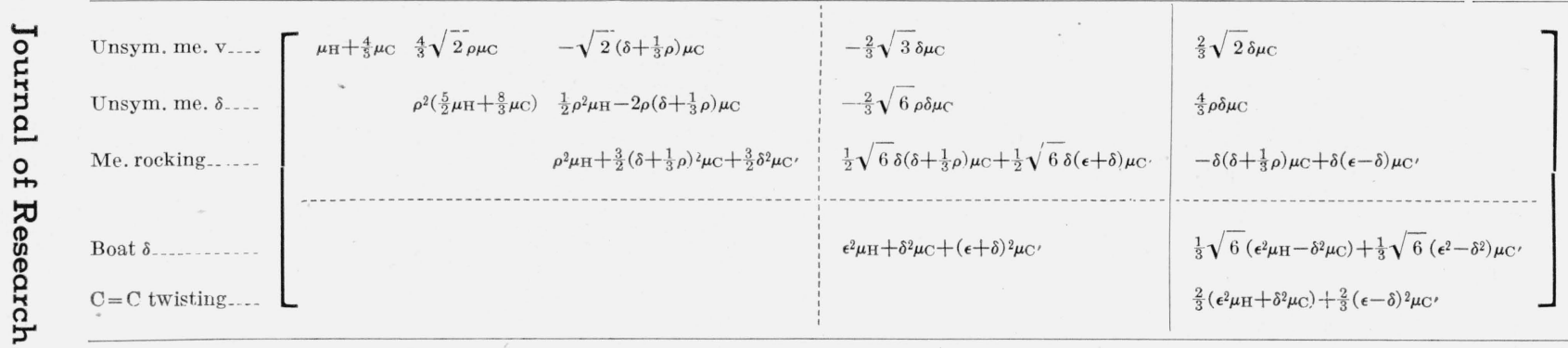




\section{Normal Equations for Nonplanar Vibrations of Propylene}

Propylene has only one element of symmetry, the plane through the three carbon atoms. The vibrations therefore fall into only two classes. No attempt was made in this research to treat the planar vibrations by means of normal coordinate analysis. The high order of the matrix involved would be prohibitively laborious to handle. A reasonably certain assignment of these frequencies can be made from the spectral data alone.

The nonplanar frequencies present a somewhat more difficult problem in assignment. Because they are not so numerous as the planar frequencies the normal equations were set up.

The coordinates used are the same as for the butenes. It was not necessary (or desirable) to take some of the symmetry combinations used in the butenes and in ethylene in this case, however.

The nonplanar propylene $\mathbf{6}$ matrix (symmetry type $A^{\prime \prime}$ ) is given in table 8 .

\section{Reduction of the Order of Matrix Equations}

The matrix equations which have been derived are of an inconveniently high order. Their order may be reduced by the removal of certain relatively constant frequencies. Wilson has shown that the $\mathrm{C}-\mathrm{H}$ (stretching) frequencies may be removed from the matrix equations by setting their force constants equal to infinity [2]. The (b) matrix is reduced in order by the number of frequencies thus removed and the remaining terms are slightly modified. The modification is equivalent to that produced by a partial triangularization of the original $\mathbf{0}$ matrix about the diagonal terms corresponding to the frequencies removed. The remaining force constants are not changed. As can be seen from Rayleigh's principle [7], the remaining frequencies are all slightly increased. The increase does not exceed 2 percent for the frequencies in the range 1000 to $1500 \mathrm{~cm}^{-1}$ and decreases rapidly for the lower frequencies. Even this small effect could be compensated by a slight decrease in the remaining force constants.

The above reduction was applied to all of the $\mathrm{C}-\mathrm{H}$ frequencies and to the $\mathrm{CH}_{3} \delta$ frequencies. The reduced equations therefore apply exactly to a hypothetical molecule which can execute all of the usual deformations, with the exceptions (1) the $\mathrm{C}-\mathrm{H}$ bonds are rigid for stretching and (2) the methyl groups are rigid units for internal deformations. A methyl group may rock, however, against the connecting $\mathrm{C}-\mathrm{C}$ bond.

This approximation for the methyl group probably has a larger effect on the remaining frequencies than the one for $\mathrm{C}-\mathrm{H} \mathrm{v}$ motions. It is known, however, that methyl deformation frequencies are remarkably constant, whatever the molecule in which they are found. It would seem that there is a relatively slight coupling between a methyl group and the rest of the molecule. In any event, this model is certainly better than a simple skeletal model.

In this way the four 15 matrices for the three rigid frame butenes are reduced from the orders $10,9,5$, and 4 to $5,4,3$, and 2 , respectively. The matrix for $A^{\prime \prime}$ (out of plane) for propylene is reduced in order from 6 to 4 .

\section{Direct Assignments From Spectral Data}

\section{(a) Propylene}

The infrared absorption spectrum data used in the present assignment are from the Shell Development Co., Emeryville, Calif. [8] and from Wilson and Wells [9]. The Raman spectral data are from Ananthakrishnan [10]. The symmetry of propylene is very low, that of the point group $C_{s}$. Consequently all of its vibrational frequencies are permitted in both the infrared and Raman spectra.

The assignment of the directly observed frequencies of propylene of the present work differs only in minor details from that of Wilson and Wells [9]. No attempt was made to give detailed assignments to the $\mathrm{C}-\mathrm{H}$ stretching vibrations as there are many modes of almost identical frequency. The $\mathrm{C}-\mathrm{H} v$ vibrations were assigned the conventional values of $3050 \mathrm{~cm}^{-1}$ for the three olefinic $\mathrm{CH}$ groups and $2950 \mathrm{~cm}^{-1}$ for the three paraffinic $\mathrm{CH}$ groups. Symmetric and unsymmetric $\mathrm{CH}_{3} \delta$ vibrations were assigned the values $1370 \mathrm{~cm}^{-1}$ and $1444 \mathrm{~cm}^{-1}$, respectively. Some of the other frequencies differ by a few wave numbers from the above authors' assignment, due to small differences between the two sets of infrared data used.

In-plane $\left(A^{\prime}\right) \quad \mathrm{CH}_{3}$ and $\mathrm{CH}_{2}$ wagging, which Wilson and Wells did not assign, have been 
assigned the frequencies $1172 \mathrm{~cm}^{-1}(I R)$ and 1042 $\mathrm{cm}^{-1}(I R)$.

\section{(b) cis-2-Butene}

Gershinowitz and Wilson have reported the infrared and Raman spectra of cis-2-butene [11] but unfortunately did not determine the state of polarization of the latter spectrum. The Shell Development Co., Emeryville, Calif., has contributed an infrared spectrogram for this substance to the catalogue of infrared spectrograms of the American Petroleum Institute Research Project 44 [8]. These spectral data were used in the preliminary assignment for cis-2-butene.

cis-2-Butene, with the symmetry of the point group $\mathrm{C}_{2 v}$, has four symmetry types of vibrations. The selection rules and the symmetry characteristics of the vibrations are presented in table 11 . The approximate form of the separate vibrations of each type is given in the complete assignment of table 18 .

TABLE 11.-Symmetry properties of the vibrations, and the selection rules for cis-, ${ }^{\mathrm{a}}$ trans- ${ }^{\mathrm{b}}$ and isobutene ${ }^{\mathrm{a}}$

\begin{tabular}{|c|c|c|c|c|c|}
\hline \multicolumn{6}{|c|}{ Characters for the point groups $C_{2 v}$ and $C_{2 h}$} \\
\hline$C_{80}$ & $C_{2 h}$ & $\frac{E}{E}$ & $\begin{array}{l}C^{2} \\
C^{2}\end{array}$ & $\begin{array}{l}\sigma^{\prime} \\
\sigma_{h}\end{array}$ & $\begin{array}{l}\sigma^{\prime \prime} \\
I\end{array}$ \\
\hline $\begin{array}{l}\mathrm{A}_{1} \\
A_{2} \\
B_{1} \\
B_{2}\end{array}$ & $\begin{array}{l}\mathrm{A}_{\mathrm{g}} \\
A_{u} \\
B_{g} \\
B_{u}\end{array}$ & $\begin{array}{l}1 \\
1 \\
1 \\
1\end{array}$ & $\begin{array}{r}1 \\
1 \\
-1 \\
-1\end{array}$ & $\begin{array}{r}1 \\
-1 \\
-1 \\
1\end{array}$ & $\begin{array}{r}1 \\
-1 \\
1 \\
-1\end{array}$ \\
\hline \multicolumn{6}{|c|}{ Selection rules } \\
\hline \multicolumn{6}{|c|}{$\begin{array}{c}C_{2 v}: \text { Infrared active: } A_{1}, B_{1}, B_{2} . \\
\text { Raman active: } A_{1}, A_{2}, B_{1}, B_{2} . \\
\left(A_{1} \text { polarized; } A_{2}, B_{1}, \text { and } B_{2} \text { depolarized }\right)\end{array}$} \\
\hline \multicolumn{6}{|c|}{$\begin{array}{c}C_{2 h}: \text { Infrared active: } A_{u}, B_{u} \\
\text { Raman active: } A_{g}, B_{g} . \\
\left(A_{g} \text { polarized, } B_{g} \text { depolarized) }\right.\end{array}$} \\
\hline
\end{tabular}

a Symmetry type $C_{2 \text { v }}$.

b Symmetry type $C_{2 \hbar}$.

The value $2950 \mathrm{~cm}^{-1}$ was assigned to the six methyl $\mathrm{C}-\mathrm{H} \mathrm{v}$ vibrations and $3050 \mathrm{~cm}^{-1}$ to the two olefinic $\mathrm{C}-\mathrm{H}$ vibrations. The value 1450 $\mathrm{cm}^{-1}$ was assigned to the four unsymmetrical methyl $\delta$ vibrations and $1380 \mathrm{~cm}^{-1}$ to the two symmetrical methyl $\delta$ motions. These motions invariably give rise to frequencies of about these magnitudes and are too numerous in this case to separate definitely.
The strong infrared absorption maximum at $1672 \mathrm{~cm}^{-1}$ is obviously the $\mathrm{C}=\mathrm{C}$ v motion. The three lowest frequencies, $304 \mathrm{~cm}^{-1}(R), 402 \mathrm{~cm}^{-1}$ $(R)$, and $583 \mathrm{~cm}^{-1}(I R, R)$ are undoubtedly the two planar skeletal $\delta$ and the $\mathrm{C}=\mathrm{C}$ twisting motions, respectively. Normal coordinate analysis confirmed this assignment, indicating $304 \mathrm{~cm}^{-1}$ for $A_{1}, 402$ for $A_{2}$, and 583 for $B_{2}$ skeletal deformations, respectively.

The lines at 876 and $978 \mathrm{~cm}^{-1}$ are probably $A_{1}$ and $B_{2} \mathrm{C}-\mathrm{C}$ v frequencies, respectively. The $\mathrm{CH}$ planar waggings $\left(A_{1}\right.$ and $\left.B_{2}\right)$ should lie in the neighborhood of $1300 \mathrm{~cm}^{-1}$ and the methyl rocking frequencies about 1000 to $1100 \mathrm{~cm}^{-1}$. A definite assignment of these latter motions and of the $\mathrm{C}-\mathrm{H}$ out-of-plane $\left(A_{2}\right.$ and $\left.B_{1}\right)$ motions was postponed until after the complete normal coordinate treatment.

\section{(c) trans-2-Butene}

Infrared and Raman spectral data from the same two sources as for cis-2-butene were used in the assignment for this molecule. Fortunately Gershinowitz and Wilson have obtained polarization data for the Raman spectrum. It is therefore possible to distinguish certain symmetry types. Frequencies with the symmetries $A_{g}$ and $B_{g}$ are Raman active, infrared inactive (table 11), with the former polarized and the latter depolarized. The other two classes, $A_{u}$ and $B_{u}$, are active only in the infrared.

The $\mathrm{C}-\mathrm{H}$ v and $\mathrm{CH}_{3} \delta$ vibrations were assigned as in cis-2-butene. Outside of these two frequency ranges there are four polarized Raman lines: 1681, 1309, 870, and $507 \mathrm{~cm}^{-1}$. These frequencies undoubtedly represent $\mathrm{C}=\mathrm{C} v, \mathrm{C}-\mathrm{H}$ wagging, $\mathrm{C}-\mathrm{C} v$, and skeletal bending, all of symmetry $\mathrm{A}_{g}$. There remains, therefore, only one vibration of symmetry $\mathrm{A}_{\mathrm{g}}$ unassigned, $\mathrm{CH}_{3}$ wagging.

Outside of the $\mathrm{C}-\mathrm{H}$ v and $\mathrm{CH}_{3} \delta$ frequency ranges there are three depolarized Raman lines, at 1043,746 , and $210 \mathrm{~cm}^{-1}$. The first two must be $\mathrm{CH}_{3}$ and $\mathrm{CH}$ wagging, respectively, with the symmetry $B_{g}$. The lowest line probably arises from the $B_{g}$ methyl torsional mode of vibration. This judgment is confirmed by the fact that 210 $\mathrm{cm}^{-1}$, symmetry $B_{g}$, corresponds to a restricting potential for the methyl groups of about 2,000 $\mathrm{cal} / \mathrm{mole}$, in agreement with the value 1,950 cal/mole determined by calorimetric data [15]. The other $\mathrm{CH}_{3}$ torsional frequency has the sym- 
metry $A_{u}$ and therefore could appear only in the infrared spectrum.

The strong infrared band centered at $964 \mathrm{~cm}^{-1}$ was assigned to $A_{u} \mathrm{CH}$ wagging. It would be expected that such an out-of-plane motion would have a large dipole moment and would show strong $P, Q$, and $R$ branches. The $A_{u}$ methyl wagging frequency was not selected from the spectrum, for no band seems certainly to be due to this motion. The other $A_{u}$ frequency, $\mathrm{C}=\mathrm{C}$ twisting, should lie at about 250 to $300 \mathrm{~cm}^{-1}$, according to preliminary rough normal calculations. This is below the range of the available infrared data.

In this molecule $B_{u}$ vibrations appear to exhibit a double minimum in the infrared absorption spectrum. Bands of this nature at 1304 and 1065 $\mathrm{cm}^{-1}$ were selected for $B_{u} \mathrm{CH}$ wagging and $\mathrm{C}-\mathrm{C} \mathrm{v}$. The shoulder, at about $964 \mathrm{~cm}^{-1}$, on the strong $A_{u}$ band at $973 \mathrm{~cm}^{-1}$, was selected for $B_{u} \mathrm{CH}_{3}$ wagging. The other $B_{u}$ vibration, skeletal bending, should have the value of about $300 \mathrm{~cm}^{-1}$, which is below the range of the spectral data.

\section{(d) Isobutene}

Infrared spectral data from the Shell Development Co., Emeryville, Calif. [8] and Raman data from Kirmann [12] and Telfair and Pielemeier [13] were used in the assignment for isobutene.

The symmetry of isobutene is the same as that of cis-2-butene, $C_{2 v}$, and therefore the selection rules are the same. The classifications of the various frequencies among the four symmetry types differ somewhat, however (table 20).

The $\mathrm{C}-\mathrm{H}$ v and $\mathrm{CH}_{3} \delta$ vibrations were assigned as in cis-2-butene. The vibrations with the symmetry $A_{1}$ were assigned as follows: The value $1664 \mathrm{~cm}^{-1}(I R, R(p))$ was assigned to $\mathrm{C}=\mathrm{C} \mathrm{v}$, the vibration $800 \mathrm{~cm}^{-1}(I R, R(p))$ to $\mathrm{C}-\mathrm{C}$ v, 1390 $\mathrm{cm}^{-1}(I R, R(p))$ to $\mathrm{CH}_{2} \delta, 1053 \mathrm{~cm}^{-1}(I R, R(p))$ to $\mathrm{CH}_{3}$ wagging, and $378 \mathrm{~cm}^{-1}(R)$ to skeletal deformation. This accounts for all the $A_{1}$ vibrations and leaves no polarized Raman lines unaccounted for.

In the symmetry class $B_{2}$ the assignment is not quite as certain as it is in class $A_{1}$. The $B_{2}$ skeletal deformation is certainly $431 \mathrm{~cm}^{-1}(I R, R) .^{5}$ Probably $986 \mathrm{~cm}^{-1}(I R)$ and $1280 \mathrm{~cm}^{-1}(I R)$ are $B_{2} \mathrm{C}-\mathrm{C}$ v and unsymmetrical $\mathrm{CH}_{2}$ bending,

${ }^{5}$ D. C. Smith, U. S. Naval Research Laboratory, reports in a private communication a strong infrared band at $432 \pm 2 \mathrm{~cm}^{-1}$. respectively. $B_{2} \mathrm{CH}_{3}$ wagging is left unassigned for the moment.

The weak unpolarized line in the Raman spectrum at $700 \mathrm{~cm}^{-1}$ is likely due to $A_{2} \mathrm{C}=\mathrm{C}$ twisting. $A_{2}$ methyl rocking will be assigned later.

The very strong infrared band at $888 \mathrm{~cm}^{-1}$ is probably due to $B_{1} \mathrm{CH}_{2}$ wagging, as in the analogous cases of cis- and trans-2-butene. No band is obviously due to methyl wagging. The probable frequency of $B_{1}$ skeletal bending lies below the range of the infrared data. There appears to be no line in the Raman spectrum from this source.

\section{Potential Constants}

(a) In-Plane Motions

The value $1.08^{6}$ was taken for the methyl rocking constant, $F_{r}$, from the work of Stitt [14]. A variety of values were tried for the $\mathrm{C}-\mathrm{C}$ v constant, $F_{\mathrm{CC}}$, but as one seemed to have no decided advantage over another, the value 7.64 from the work of Wilson and Wells was used in the final computations. The $\mathrm{C}=\mathrm{C}_{\mathrm{v}}$ constant, 16.40 , from the present work on ethylene apparently is too high for the butenes. It was reduced to 15.40 in order to fit the observed $\mathrm{C}=\mathrm{C} v$ frequencies.

The pattern of bending constants determined for ethylene was used as a guide in estimating the bending constants for the butenes. It was not practicable to utilize the full set of interaction bending constants as was done in the case of ethylene.

In table 12 the in-plane bending constants which were used are Jisted, together with the angle to which each corresponds.

TABLE 12.-In-plane bending force constants and the associated angles

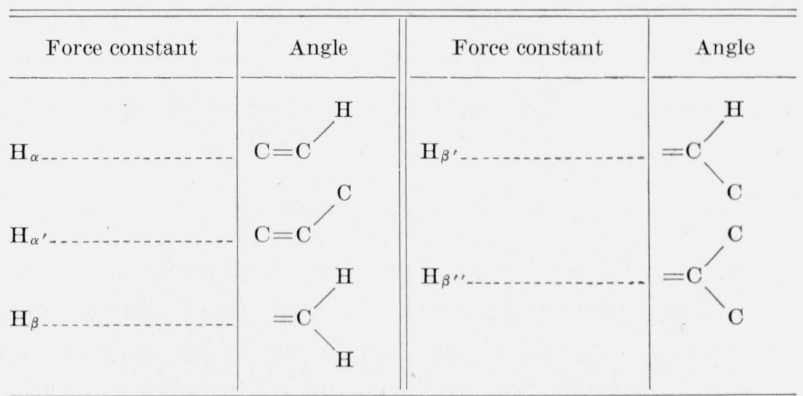

Preliminary calculations showed that $H_{\alpha^{\prime}}$ has a value about 60 percent greater than $H_{\alpha}$ from

${ }^{6}$ The values of the potential constants given in this section are expressed in angstrom-atomic weight units, as previously described. 
ethylene. The following relations were therefore assumed:

$$
\begin{gathered}
H_{\alpha^{\prime}}=1.6 H_{\alpha} \\
H_{\beta^{\prime}}=1.3 H_{\beta} \\
H_{\beta^{\prime \prime}}=1.6 H_{\beta}
\end{gathered}
$$

The interaction between $\mathrm{C}=\mathrm{C}$ v and $\mathrm{C}=\mathrm{C}-\mathrm{H} \delta$ was found to be by no means negligible in ethylene. In the butenes it was assumed that the interaction $l_{C \alpha^{\prime}}$ is 1.3 greater than the value of $\left(l_{C \alpha}-l_{C \beta}\right)$ found in ethylene. The value of $l_{C \beta}$ is probably much smaller than that of $l_{C \alpha}$ and was neglected.

The if matrices for the in-plane vibrations of cis-, trans-, and isobutene are given in table 13 .

TABLE 13.-Reduced matrices for the in-plane vibrations of cis-, trans-, and isobutene

cis-2-Butene, $A_{1}$, and trans-2-Butene, $A_{g}$ a

$$
\left[\begin{array}{lllll}
F_{r} & & & & \\
& F_{\mathrm{CC}} & & & \\
& & H_{\alpha}+H_{\beta^{\prime}} & H_{\beta^{\prime}} & \sqrt{2} l_{\mathrm{C} \alpha} \\
& & H_{\alpha^{\prime}}+H_{\beta^{\prime}} & \sqrt{2} l_{\mathrm{C}^{\prime}}{ }^{\prime} \\
& & & & K_{\mathrm{CC}}
\end{array}\right]
$$

Isobutene, $A_{1}$

$$
\left[\begin{array}{lllll}
F_{r} & & & & \\
& F_{\mathrm{CC}} & & & \\
& H_{\alpha}+2 H_{\beta} & & \sqrt{2} l_{\mathrm{C} \alpha} \\
& & H_{\alpha^{\prime}}+2 I_{\beta^{\prime}}{ }^{\prime \prime} & \sqrt{2} l_{\mathrm{C} \alpha^{\prime}} \\
& & & & K_{\mathrm{CC}}
\end{array}\right]
$$

Isobutene, $B_{2}$

$$
\left[\begin{array}{llll}
F_{\mathrm{r}} & & & \\
& F_{\mathrm{CC}} & & \\
& & H_{\alpha} & \\
& & & H_{\alpha^{\prime}}
\end{array}\right]
$$

a The matrices for cis-2-Butene $B_{2}$ and trans-2-Butene $B_{u}$ are the same as the above matrix without the last column $(\mathrm{C}=\mathrm{C} \mathrm{v})$.

\section{(b) Out-of-Plane Motions}

The symbol $F_{\varphi_{i}}$ is used for the potential constant of torsion between the planes of the groups at either end of the olefinic bond. The subscripts $i$ and $j$ identify the two groups. The subscript 0 is used for $=\mathrm{CH}_{2}, 1$ for $=\mathrm{CH}\left(\mathrm{CH}_{3}\right)$ and 2 for $=\mathrm{C}\left(\mathrm{CH}_{3}\right)_{2}$.

The potential constant for the change in the angle between the $\mathrm{C}=\mathrm{C}$ bond and the plane of the attached group is designated $F_{\gamma_{i}}$, where $i$ has the values 0,1 , and 2 as above. The symbol $f_{\gamma \gamma}$ is used for the interaction constant between the two $\gamma$ angles of a molecule.

In order to fit the observed out-of-plane frequencies it was necessary to include an interaction constant $f_{\gamma \varphi}$ between $\gamma_{1}$ and $\phi$ out-of-plane distortions.

In a preliminary calculation it was found that $F_{\gamma}$ and $f_{\gamma \gamma}$ have about the same values in propylene and the butenes as in ethylene but that $F_{\varphi}$ exhibits a trend upward with increase in the number of attached methyl groups. Since the order of the matrices involved is small, it was possible then to make further slight adjustments in order to improve the fit with the observed frequencies.

The $\mathfrak{i f}$ matrices for the out-of-plane frequencies of propylene, cis-, trans-, and isobutene are given symbolically in table 14 .

TABLE 14.-Reduced if matrices for the out-of-plane vibrations of propylene, cis-, trans-, and isobutene

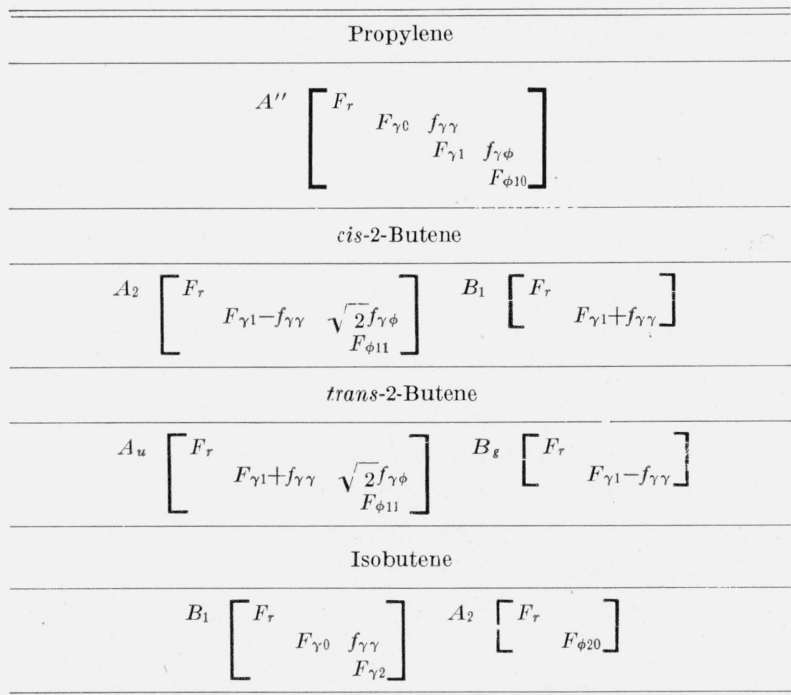

For cis- and trans-2-butene, $F_{\gamma_{1}}-f_{\gamma \gamma}$ and $F_{\gamma_{1}}+f_{\gamma \gamma}$ were found to have the values 0.37 and 0.45 , respectively. A value of -0.09 was determined for $f_{\gamma \varphi}$ and 1.08 for $F_{\varphi_{11}}$.

In isobutene, $F_{\gamma_{0}}$ was set equal to 0.35 in order to fit approximately the observed frequency at $888 \mathrm{~cm}^{-1} . \quad F_{\gamma_{0}}$ and $F_{\gamma_{2}}$ were made to average the same as $F_{\gamma_{1}}$ from cis- and trans-2-butene. Therefore, $F_{\gamma_{2}}=0.47$. The interaction constant $f_{\gamma \gamma}$ was given the same value as in the two preceding molecules, 0.04 . The torsional constant $F_{\varphi_{20}}$ was found to have the value 0.83 by comparison with the observed frequency at $700 \mathrm{~cm}^{-1}$. 
In propylene, $F_{\gamma_{0}}$ and $F_{\gamma_{1}}$ were taken as the mean of the values of $\mathfrak{H}_{\gamma}$ from ethylene and of $F_{\gamma_{0}}$ and $F_{\gamma_{2}}$ in isobutene giving 0.37 and 0.43 , respectively. Giving $f_{\gamma \gamma}$ the usual value of 0.04 , one selects $F_{\varphi_{10}}=0.85$ to fit the $580 \mathrm{~cm}^{-1}$ frequency in the propylene spectrum.

The increase from $F_{\varphi_{00}}=0.59$ to $F_{\varphi_{10}}=0.85$ to $F_{\varphi_{11}}=1.08$ is reasonably regular. The value of 0.83 for $F_{\varphi_{20}}$ from isobutene seems anomalous, but unless a new line is found in the spectrum there appears to be no alternative.

\section{Calculated Frequencies}

The values calculated for the in-plane frequencies of $c i s-$, trans-, and isobutene from the potential constants of section 5 (a) are compared with the observed frequencies in table 15 . The observed frequencies marked with an asterisk $(*)$ were not used as guides in the adjustment of the potential constants.

The same comparison for the out-of-plane frequencies is given in table 16 .

TABLE 15.-Comparison of calculated and observed frequencies, in wave numbers, for in-plane vibration

\begin{tabular}{|c|c|c|c|c|}
\hline Compound & $\begin{array}{l}\text { Calcu- } \\
\text { lated }\end{array}$ & Observed & $\begin{array}{l}\text { Calcu- } \\
\text { lated }\end{array}$ & Observed \\
\hline \multirow[b]{2}{*}{ cis-2-Butene-... } & \multicolumn{2}{|c|}{$A_{1}$} & \multicolumn{2}{|c|}{$B_{2}$} \\
\hline & $\begin{array}{r}1671 \\
1242 \\
1016 \\
911 \\
238\end{array}$ & $\begin{array}{r}1672 \\
{ }^{*} 1267 \\
{ }^{*} 1018 \\
876 \\
a 304\end{array}$ & $\begin{array}{r}1473 \\
1099 \\
972 \\
586 \\
\end{array}$ & $\begin{array}{r}1390 \\
{ }^{*} 1040 \\
978 \\
581 \\
\ldots . .\end{array}$ \\
\hline \multirow{3}{*}{ trans-2-Butene } & \multicolumn{2}{|c|}{$A_{g}$} & \multicolumn{2}{|c|}{$B_{u}$} \\
\hline & $\begin{array}{r}1693 \\
1342 \\
1080 \\
920 \\
473\end{array}$ & $\begin{array}{c}1681 \\
1309 \\
870 \\
507\end{array}$ & $\begin{array}{r}1353 \\
1070 \\
974 \\
308 \\
\end{array}$ & $\begin{array}{r}1304 \\
1065 \\
973 \\
\end{array}$ \\
\hline & \multicolumn{2}{|c|}{$A_{1}$} & \multicolumn{2}{|c|}{$B_{2}$} \\
\hline Isobutene.... & $\begin{array}{r}1666 \\
1457 \\
1002 \\
776 \\
380\end{array}$ & $\begin{array}{r}1664 \\
1390 \\
1053 \\
800 \\
378\end{array}$ & $\begin{array}{r}1397 \\
1007 \\
963 \\
438 \\
\end{array}$ & $\begin{array}{c}1280 \\
986 \\
431 \\
\end{array}$ \\
\hline
\end{tabular}

a This frequency of cis-2-butene is observed to be considerably higher than the calculated value. The motion, symmetric in-plane skeletal deformation, involves a rather close approach of the two methyl groups. The additional potential energy from this source probably accounts for the increase in the frequency over the simple calculated value.
TABLE 16.-Comparison of calculated and observed frequencies, in wave numbers, for out-of-plane vibrations

\begin{tabular}{|c|c|c|c|c|}
\hline Compound & $\begin{array}{l}\text { Calcu- } \\
\text { lated }\end{array}$ & Observed & $\begin{array}{l}\text { Calcu- } \\
\text { lated }\end{array}$ & Observed \\
\hline \multirow{3}{*}{ cis-2-Butene... } & \multicolumn{2}{|c|}{$A_{2}$} & \multicolumn{2}{|c|}{$B_{1}$} \\
\hline & $\begin{array}{r}1049 \\
951 \\
401\end{array}$ & 402 & $\begin{array}{r}1028 \\
686 \\
\end{array}$ & $\begin{array}{r}1046 \\
685 \\
\end{array}$ \\
\hline & \multicolumn{2}{|c|}{$A_{u}$} & \multicolumn{2}{|c|}{$B_{g}$} \\
\hline \multirow[t]{2}{*}{ trans-2-Butene.. } & $\begin{array}{r}1030 \\
960 \\
260\end{array}$ & 964 & $\begin{array}{r}1045 \\
746 \\
\end{array}$ & $\begin{array}{r}1043 \\
746 \\
\end{array}$ \\
\hline & \multicolumn{2}{|c|}{$B_{1}$} & \multicolumn{2}{|c|}{$A_{2}$} \\
\hline \multirow[t]{2}{*}{ Isobutene } & $\begin{array}{r}1066 \\
897 \\
391\end{array}$ & 888 & $\begin{array}{r}988 \\
701 \\
\end{array}$ & 700 \\
\hline & \multicolumn{2}{|c|}{$A^{\prime \prime}$} & & \\
\hline Propylene_ & $\begin{array}{r}1049 \\
974 \\
929 \\
573\end{array}$ & $\begin{array}{l}990 \\
911 \\
580\end{array}$ & W & , \\
\hline
\end{tabular}

\section{The Complete Assignments}

The complete vibrational frequency assignments of propylene, cis-, trans-, and isobutene are presented in tables 17, 18, 19, and 20. The descriptions of the motion are only approximate. Each mode of vibration actually involves a linear combination of all the elementary symmetry modes, but with one type usually predominating. The symbols after each frequency give its origin, according to the following scheme: $I R$ for infrared, $R$ for Raman, $p$ for polarized, $d p$ for depolarized, $c$ for conventional value and $*$ for calculated.

The two skeletal deformations of trans-2-butene were lowered from the calculated values of 260 and $308 \mathrm{~cm}^{-1}$ to $240 \mathrm{~cm}^{-1}$ and $290 \mathrm{~cm}^{-1}$, respectively, in order that the restricting potential for the rotation of the methyl groups, calculated from calorimetric data and the remainder of the above assignment, should agree with the barrier to methyl rotation calculated from the $210 \mathrm{~cm}^{-1}$ Raman line which in turn agrees with the value of the barrier determined for propylene [15]. 
TABLE 17.-Vibrational frequency assignment of propylene, in wave numbers

\begin{tabular}{|c|c|c|c|c|}
\hline Type of vibration & \multicolumn{2}{|c|}{$A^{\prime}$} & \multicolumn{2}{|c|}{$A^{\prime \prime}$} \\
\hline $\mathrm{C}-\mathrm{H}$ v (ethylenic)... & (3) 3050 & $c$ & & \\
\hline $\mathrm{C}-\mathrm{H}$ v (methyl) & (2) 2950 & $c$ & 2950 & $c$ \\
\hline $\mathrm{C}=\mathrm{C} \mathrm{v} \ldots \ldots$ & 1649 & $I R, R(p)$ & ......... & ... \\
\hline $\mathrm{C}-\mathrm{C} \vee \ldots$ & 920 & $I R, R(p)$ & .......... & \\
\hline $\mathrm{CH}_{3}$ unsym. $\delta \ldots$ & 1444 & $I R, R-$ & 1444 & $I R, R$ \\
\hline $\mathrm{CH}_{3}$ sym. $\delta \ldots \ldots$ & 1370 & $c$ & ........ & ........ \\
\hline $\mathrm{CH}_{2} \delta \ldots \ldots \ldots$ & 1415 & $I R, R(p)$ & ......... & ........ \\
\hline $\mathrm{CH}_{3}$ wagging $\ldots . . . .$. & 1042 & $I R$ & 1050 & $(*)$ \\
\hline $\mathrm{CH}_{2}$ wagging ........ & 1172 & $I R$ & 911 & $I R$ \\
\hline CH wagging ........... & 1297 & $I R, R(p)$ & 580 & $I R, R(d p)$ \\
\hline Skeletal $\delta \ldots$ & 417 & $R(p)$ & $\ldots 1$ & $\ldots \ldots$ \\
\hline $\mathrm{C}=\mathrm{CH}_{2}$ twisting $\ldots$ & -....... & - & 990 & $I R$ \\
\hline
\end{tabular}

TABLE 18.-Vibrational frequency assignment of cis-2-butene, in wave numbers

\begin{tabular}{|c|c|c|c|c|c|c|c|c|}
\hline Type of vibration & \multicolumn{2}{|c|}{$A_{1}$} & \multicolumn{2}{|c|}{$A_{2}$} & \multicolumn{2}{|c|}{$B_{1}$} & \multicolumn{2}{|c|}{$B_{2}$} \\
\hline $\mathrm{C}-\mathrm{H} \vee$ (ethylenic). & 3050 & $c$ & $\ldots$ & $\ldots$ & - & & 3050 & $c$ \\
\hline $\mathrm{C}-\mathrm{H}$ v (methyl) ... & (2) 2950 & $c$ & 2950 & $c$ & 2950 & $c$ & (2) 2950 & $c$ \\
\hline $\mathrm{C}=\mathrm{C} \mathrm{v}_{\ldots} \ldots$ & 1672 & $R, I R$ & $\ldots$ & -... & - . . & & - & \\
\hline $\mathrm{C}-\mathrm{C} \mathrm{v}_{\ldots}$ & 876 & $I R$ & $\ldots$ & $\ldots$ & ........ & & 978 & $R, I R$ \\
\hline $\mathrm{CH}_{3} \delta$ unsym & 1450 & $c$ & 1450 & $c$ & 1450 & $c$ & 1450 & $c$ \\
\hline $\mathrm{CH}_{3} \delta \mathrm{sym}_{\ldots} \ldots$ & 1380 & $c$ & $\ldots$ & .... & - n. & & 1380 & $c$ \\
\hline $\mathrm{CH}_{3}$ wagging & 1018 & $R, I R$ & 950 & $(*)$ & 1040 & $(*)$ & 1064 & $I R$ \\
\hline $\mathrm{CH}$ wagging & 1267 & $R$ & 1050 & $(*)$ & 673 & $R, I R$ & 1390 & $R, I R$ \\
\hline Skeletal $\delta \ldots$ & 304 & $R$ & 402 & $R$ & -....... & - . . . & 583 & $R$ \\
\hline
\end{tabular}

TABLE 19.-Vibrational frequency assignment of trans-2-butene, in wave numbers

\begin{tabular}{|c|c|c|c|c|c|c|}
\hline Type of vibration & \multicolumn{2}{|c|}{$A_{g}$} & $A_{u}$ & $B_{g}$ & \multicolumn{2}{|l|}{$B_{u}$} \\
\hline $\mathrm{C}-\mathrm{H}$ v (ethylenic) & 3050 & $c$ & $\ldots$ & -..... & 3050 & $c$ \\
\hline $\mathrm{C}-\mathrm{H}$ v (methyl) & (2) 2950 & $c$ & $2950 \quad c$ & $2950 \quad c$ & (2) 2950 & $c$ \\
\hline $\mathrm{C}=\mathrm{C} \mathrm{v}_{\ldots} \ldots$ & 1681 & $R(p)$ & $\ldots$ & $\ldots$ & ..... - & . \\
\hline $\mathrm{C}-\mathrm{C} \mathrm{v} \ldots \ldots$ & 870 & $R(p)$ & - n. & -..... & 1065 & $I R$ \\
\hline $\mathrm{CH}_{3} \delta$ unsym $\ldots . .$. & 1450 & $c$ & $1450 \quad c$ & $1450 \quad c$ & 1450 & $c$ \\
\hline $\mathrm{CH}_{3} \delta \mathrm{sym} \ldots \ldots$ & 1380 & $c$ & $\ldots \ldots$ & -n & 1380 & $c$ \\
\hline $\mathrm{CH}_{3}$ wagging ...... & 1080 & $(*)$ & $1030 \quad(*)$ & $1043 \quad R(d p)$ & 973 & $I R$ \\
\hline $\mathrm{CH}$ wagging $\ldots . . . .$. & 1309 & $R(p)$ & $964 I R$ & $746 \quad R(d p)$ & 1304 & $I R$ \\
\hline Skeletal $\delta \ldots \ldots$ & 507 & $R(p)$ & $240 \quad(*)$ & - n & 290 & $(*)$ \\
\hline
\end{tabular}

TABLE 20.-Vibrational frequency assignment of isobutene, in wave numbers

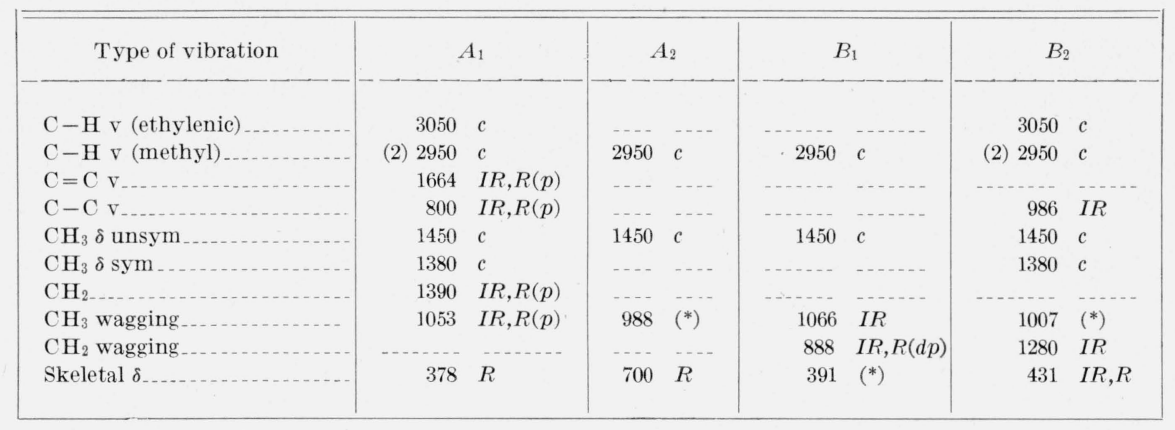




\section{References}

[1] W. S. Gallaway and E. F. Barker, J. Chem. Phys. 10, 88 (1942).

[2] E. B. Wilson, Jr., J. Chem. Phys. 9, 76 (1941).

[3] A. G. Meister, F. F. Cleveland, and M. J. Murray, Am. J. Phys. 11, 239 (1943).

[4] J. E. Rosenthal and G. M. Murphy, Rev. Modern Phys. 8, 317 (1936).

[5] G. Herzberg, Infrared and Raman spectra of polyatomic molecules (D. Van Nostrand Co., Inc., New York, N. Y.)

[6] Y. L. Tchang, Ann. Soc. Sci. Bruxelles [1] 58, 87 (1938).

[7] Rayleigh, The theory of sound (The Macmillan Co., New York, N. Y.)

[8] American Petroleum Institute Research Project 44 at the National Bureau of Standards. Catalog of
Infrared Spectrograms. Serial Nos. 19, 21, 22, 23; Propylene, cis-2-butene, trans-2-butene, and isobutene. Contributed by the Shell Development Co., Emeryville, Calif.

[9] E. B. Wilson, Jr. and A. J. Wells, J. Chem. Phys, 9, 319 (1941).

[10] R. Ananthakrishnan, Proc. Ind. Acad. Sci. 3a, 527 (1936).

[11] H. Gershinowitz and E. B. Wilson, Jr., J. Chem. Phys. 6, 247 (1938).

[12] A. Kirrmann, Bul. Soc. Chim. [5] 6, 845 (1939).

[13] D. Telfair and W. H. Pielemeier, Rev. Sci. Instr. 13, 122 (1942).

[14] F. Stitt, J. Chem. Phys. 7, 297 (1939).

[15] J. E. Kilpatrick and K. S. Pitzer, J. Research NBS 37, (1946) RP1738.

Washington, May 29, 1946. 